\title{
Pyroptosis, a New Breakthrough in Cancer Treatment
}

\author{
Dengqiang $W u^{1}$, Changhong $W e^{1}$, Yujie $L i^{2}$, Xuejia Yang ${ }^{1}$ and Sufang Zhou ${ }^{1,2^{*}}$ \\ ${ }^{1}$ National Center for International Research of Bio-targeting Theranostics, Guangxi Key Laboratory of Bio-targeting \\ Theranostics, Collaborative Innovation Center for Targeting Tumor Diagnosis and Therapy, Guangxi Talent Highland of Bio- \\ targeting Theranostics, Guangxi Medical University, Nanning, China, ${ }^{2}$ Department of Biochemistry and Molecular Biology, \\ School of Pre-Clinical Science, Guangxi Medical University, Nanning, China
}

OPEN ACCESS

Edited by:

Shiv K. Gupta,

Mayo Clinic, United States

Reviewed by:

Zhifang Zhang, Beckman Research Institute, City of Hope, United States Xiaoyu Luo, University of California, San Francisco, United States

*Correspondence: Sufang Zhou zsf200000@163.com

Specialty section: This article was submitted to Cancer Molecular

Targets and Therapeutics, a section of the journal Frontiers in Oncology

Received: 22 April 2021 Accepted: 02 July 2021 Published: 26 July 2021

Citation:

Wu D, Wei C, Li Y, Yang $X$ and Zhou S (2021) Pyroptosis, a New Breakthrough in Cancer Treatment.

Front. Oncol. 11:698811. doi: $10.3389 /$ fonc. 2021.698811
The way of cell death can be roughly divided into two categories: cell necrosis and PCD (programmed cell death). Pyroptosis is a kind of PCD, its occurrence depends on the gasdermin protein family and it will produce inflammatory response. With constant research in recent years, more and more evidences show that pyroptosis is closely related to the occurrence and development of tumors. The treatment of tumors is a big problem worldwide. We focus on whether we can discover new potential tumor markers and new therapeutic targets from the mechanism. If we can understand the mechanism of pyroptosis and clear the relationship between pyroptosis and the development of tumors, this may provide a new reference for clinical cancer treatment.

Keywords: pyroptosis, programmed cell death, gasdermin family, cancer treatment, antitumor immunity

\section{BACKGROUND}

Countless people die of tumors in the world every year (1), the prevention and treatment of tumors are very important to human health. The most conventional methods of cancer treatment are surgery, radiotherapy and chemotherapy. Pyroptosis is a type of PCD. Comparing with several other ways of death, pyroptosis occurs faster than others. And it is accompanied with a strong inflammatory response in the body. In recent years, more and more studies have shown that there was a close relationship between pyroptosis and tumors (2).

In 1986, Friedlander discovered that the use of anthrax lethal toxin could induce rapid lytic death of mouse macrophages, accompanied with non-specific leakage of intracellular materials (3). In 1992,

\footnotetext{
Abbreviations: PCD, programmed cell death; IL-1 $\beta$, interleukin-1 $\beta$; IL-18, interleukin-18; GSDMD, gasdermin D; GSDM NT, gasdermin N-terminal; GSDM CT, gasdermin C-terminal; NLRP1, NLR family pyrin domain containing 1; NLRP3, NLR family pyrin domain containing 3; NLRC4, NOD-like receptor containing a caspase activating and recruitment domain 4; AIM2, absent in melanoma2; ASC, adaptor protein apoptosis associated speck like proteins; LPS, lipopolysaccharide; DFNA5, deafness autosomal dominant 5; GSDME, gasdermin E; ROS, reactive oxygen species; GZMB, Granzyme B; LDH, lactate dehydrogenase; NSCLC, nonsmall-cell lung cancer; siRNA, small interfering RNA; MIP, macrophage inflammatory protein; IP-10, interferon-inducible protein-10; TTM, Trillium tschonoskii Maxim; PPVI, Polyphyllin VI; PG, Emodin 80O- $\beta$ glucopyranoside; miRNA, microRNA; DHA, docosahexaenoic acid; PD-L1, programmed death ligand 1; PD-1, programmed cell death protein 1; nPD-L1, nuclear programmed death ligand 1; GSDMC, gasdermin C; HCC, hepatocellular carcinoma; E2, 17ß-estradiol; AIF, Alpinumisoflavone; 5-FU, 5-Fluorouracil; ERK, extra Cellular signal-regulated kinase; STAT3, Signal Transducer and Activator of Transcription 3; PI3K, phosphatidylinositol 3 kinase; NK cell, natural killer cell; TILs, tumor infiltrating lymphocytes; PFN, perforin; CAR-T, chimeric antigen receptor T cell; CRS, cytokine release syndrome; CTL, Cytotoxic T Lymphocyte.
} 
Zychlinsky et al. found that it was morphologically different from the well-known apoptosis (4). At that time, they believed that it was a kind of PCD caused by the activation of caspase-1. In 1999, D. Hersh et al. showed that cell death caused by Salmonella Shigella could be blocked if caspase-1 was knocked out (5). In 2001, Cookson BT et al. first described this type of PCD accompanied with inflammation as pyroptosis (6), and distinguished this new form of cell death from others. Fink SL et al. defined pyroptosis in 2005 as caspase-1-mediated PCD that the cell underwent nuclear constriction, DNA fragmentation, swelling and finally rupture, accompanied with the release of inflammatory factors such as IL$1 \beta$ (interleukin-1 $\beta$ ) and IL-18 (interleukin-18) (7). GSDMD (gasdermin D) was identified as a key protein of pyroptosis in 2015, and study showed that caspase-1/4/5/11 could all cut the GSDMD protein $(8,9)$. One year later in 2016 , further mechanism studies clarified that GSDMD-NT could oligomerize in biomembranes to form pores (10). Doctor Feng Shao reported that multiple gasdermin-N domain had the function of poreforming and could induce pyroptosis in the same year (11). In 2017, Shi J et al. redefined the concept of pyroptosis as programmed cell necrosis mediated by gasdermin family proteins (12).

In 2018, NCCD (Nomenclature Committee on Cell Death) revised the definition of pyroptosis as a type of RCD (regulated cell death) that relies on the formation of cytoplasmic membrane pores by the gasdermin protein family, and its occurrence is often (but not always) as a consequence of inflammatory caspase activation (13) (Table 1).

\section{MOLECULAR MECHANISM OF PYROPTOSIS}

We have consulted the literatures on the mechanism of pyroptosis in recent years and made a certain summary.

Gasdermin was first reported in 2000 as a candidate gene for murine skin mutations. Since the protein was mainly expressed in the gastrointestinal tract and skin of mice, and its expression was restricted to the esophagus and stomach in the gastrointestinal tract, so it was named gasdermin (14). Gasdermin protein plays a decisive role in the process of pyroptosis, which is composed of two different domains, including GSDM-NT (N-terminal) and
GSDM-CT (C-terminal) domains, and they are connected by a flexible connecting region. Without the cleavage by an activation signal, GSDM-CT can inhibit the activity of GSDM-NT by binding to it (11). Once GSDM-NT is released, it will form oligomers to play the function of drilling and induce pyroptosis (15).

\section{THE CANONICAL INFLAMMASOME- INDUCED PYROPTOSIS}

The pyroptosis mediated by the canonical pathway is mostly induced by the inflammasome complex (12). Several major inflammasomes have been discovered so far, including NLRP1 (NLR family pyrin domain containing 1) (16), NLRP3 (NLR family pyrin domain containing 3) (17), NLRC4 (NOD-like receptor containing a caspase activating and recruitment domain 4) (18), AIM2 (absent in melanoma2) (19-21) and the pyrin domain (22). These inflammasomes can sense the stimulation of various pathogenic signals, and interact with homotypic or heterotypic PYD/CARD (Caspase activation and recruitment domain). Meanwhile, they recruit the apoptosis-related dot-like protein ASC (adaptor protein apoptosis associated speck like proteins) and pro-caspase- 1 to form the inflammasome complex $(23,24)$. Then caspase- 1 is activated to cleave GSDMD to produce GSDMD-NT specifically $(8,25,26)$. At the same time, Case CL et al. found that NLRC4 could directly bind to caspase- 1 to cut GSDMD and induce pyroptosis without relying on ASC (27). Subsequently, active caspase-1 further cleave and activate pro-IL- $1 \beta$ and pro-IL- 18 by recognizing the tetrapeptide sequence. IL-1ßand IL- 18 are finally released outside the cell through the membrane pores (28) (Figure 1).

In addition to IL- $1 \beta$ and IL-18, IL-1 $\alpha(29,30)$ and HMGB1 (high mobility group protein B1) (31) will also be released when pyroptosis, too.

\section{THE NONCANONICAL INFLAMMASOME- INDUCED PYROPTOSIS}

The noncanonical inflammasome pathway is different from the canonical inflammasome pathway due to its unique formation method. It mainly depends on the activation of caspase-11 (mouse)

TABLE 1 | The discovery of pyroptosis.

\begin{tabular}{|c|c|c|c|}
\hline Year & Authors & Discovery & Refs \\
\hline In 1986 & Friedlander & $\begin{array}{l}\text { The lethal anthrax toxin induced rapid death of macrophages, accompanied with the } \\
\text { leakage of intracellular materials. }\end{array}$ & (3) \\
\hline In 1992 & Zychlinsky et al. & It was different from the common apoptosis in morphology. & (4) \\
\hline In 1999 & D. Hersh et al. & Knocking out caspase-1, Salmonella Shigella could not cause cell death. & (5) \\
\hline In 2001 & Cookson BT et al. & $\begin{array}{l}\text { It was the first time to describe this type of PCD accompanied with inflammatory } \\
\text { response as pyroptosis. }\end{array}$ & (6) \\
\hline $\ln 2005$ & Fink SL et al. & Pyroptosis was defined as a kind of PCD mediated by Caspase- 1. & $(7)$ \\
\hline In 2015 & Shi et al. & $\begin{array}{l}\text { GSDMD was identified as a key protein of pyroptosis and it was the common substrate of } \\
\text { caspase- } 1 / 4 / 5 / 11 \text {. }\end{array}$ & $(8,9)$ \\
\hline In 2016 & Liu et al. & GSDMD-NT could oligomerize in biomembranes to form pores & $(10,11)$ \\
\hline $\ln 2017$ & Shi et al. & The concept of pyroptosis was redefined as PCD mediated by gasdermin family proteins. & (12) \\
\hline In 2018 & Galluzzi L et al. & $\begin{array}{l}\text { The definition of pyroptosis was modified as a kind of RCD that depends on the } \\
\text { gasdermin protein family to form pores in cytomembrane. Its occurrence was often(but } \\
\text { not always) the result of inflammatory caspase activation. }\end{array}$ & (13) \\
\hline
\end{tabular}




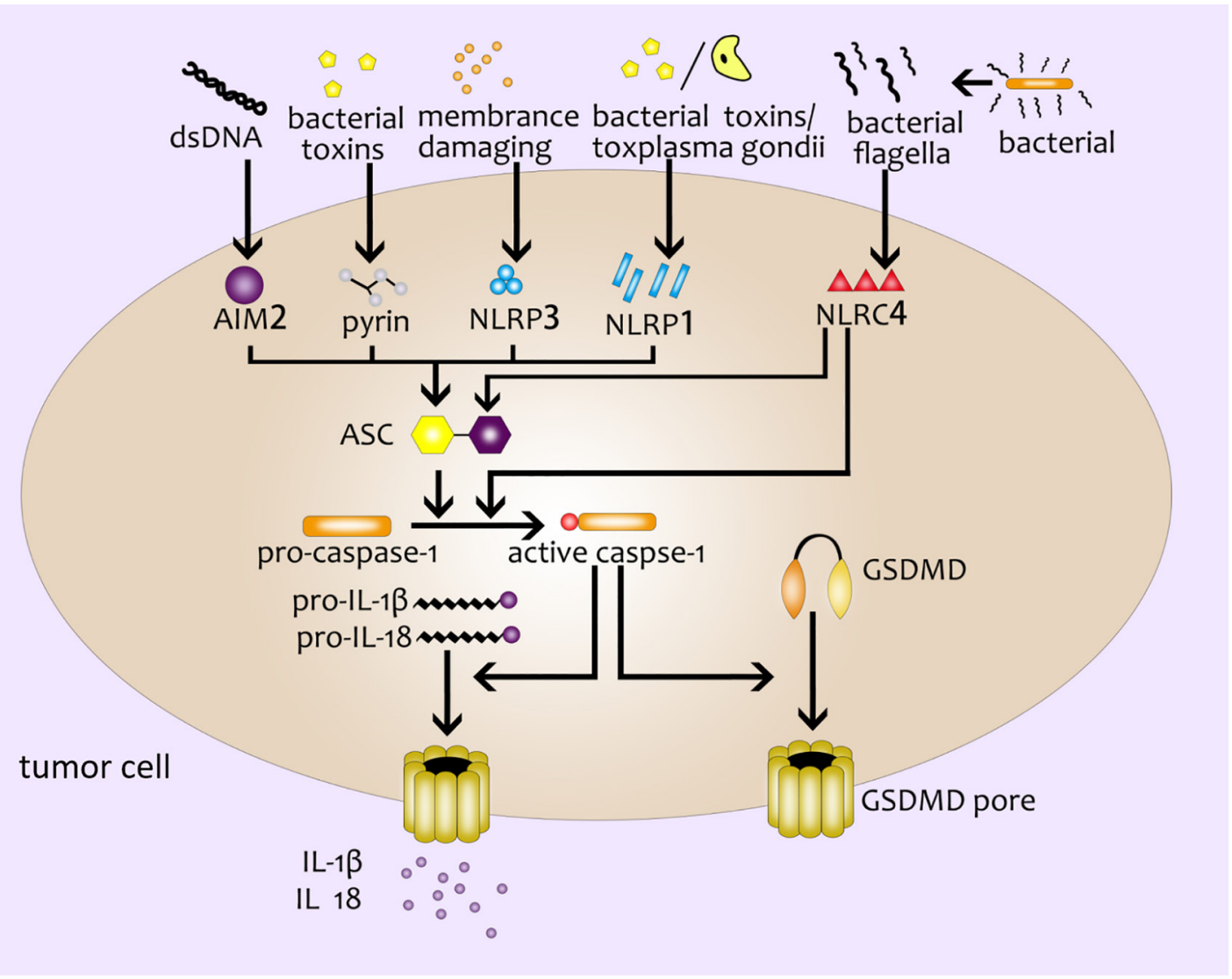

FIGURE 1 | The canonical inflammasome pathway. Double-stranded DNA, bacterial toxins, membrane-damaging agents, toxoplasma gondii, bacterial flagella and other external stimulants can activate inflammasomes in cells and further recruit ASC and pro-caspase- 1 to form inflammasome complex. Active caspase-1 cleaves GSDMD to produce GSDMD pores on the cell membrane; active caspase- 1 can activate pro-IL-1 $\beta$ and pro-IL-18, and then IL-1 $\beta$ and IL- 18 are released from the GSDMD pores.

or caspase-4/5 (human) in the caspase family $(2,12)$. Different from caspase-1, the CARD domain of caspase-11 in mouse can directly recognize and bind to the LPS (lipopolysaccharide) of gram-negative bacteria, and present proteinase activity after being activated by oligomerization (32). GSDMD-NT cleaved by active caspase-11 form pores in cell membrane to induce pyroptosis $(9,33)$. On the other hand, the activation of caspase- 11 by LPS can lead to the open of pannexin-1 (a nonselective macroporous protein channel) (34). The open of pannexin-1 can make a $\mathrm{k}+$ efflux and activate NLRP3 inflammasome, inducing caspase-1-mediated pyroptosis (as mentioned above, the canonical inflammasome pathway) $(35,36)$. As for human caspase-4/5, LPS can stimulate them directly and then trigger the noncanonical inflammasome pathway (37) (Figure 2).

\section{PYROPTOSIS MEDIATED BY OTHER GASDERMINS}

GSDME was first identified as a deaf gene in 1988, also known as DFNA5 (deafness autosomal dominant 5) (38). Researches in recent years have found that GSDME was not only related to hearing damage, but also related to the occurrence of pyroptosis closely $(39,40)$. Both canonical and non-canonical inflammasome pathways are caused by GSDMD-NT. However, Wang et al. have demonstrated that cisplatin, paclitaxel and other conventional chemotherapeutic drugs can activate caspase3. Then the active caspase-3 cleaves GSDME to form GSDMENT, which leads to the appearance of pores in the cell membrane (40). Caspase-3 is originally an enzyme related to apoptosis (4143). Wang et al. discovered that GSDME was a "switch" for chemotherapeutic drugs-induced apoptosis or pyroptosis in cancer cells. The cancer cells with high expression of GSDME undergo pyroptosis when treated with chemotherapeutic drugs while cells with low or no expression of GSDME undergo apoptosis (40). Excessive ROS (reactive oxygen species) in cells will enhance oxidative stress and cause cell necrosis. Wu et al. found that the iron-dependent intracellular ROS could be sensed by the outer mitochondrial membrane protein Tom20. And then the Bax protein translocate to the surface of the mitochondria to form a cavity, which leads to the release of cytochrome C. Cytochrome $\mathrm{C}$ activates caspase-9, and caspase- 9 further activates caspase-3, active caspase- 3 induces GSDME-mediated 


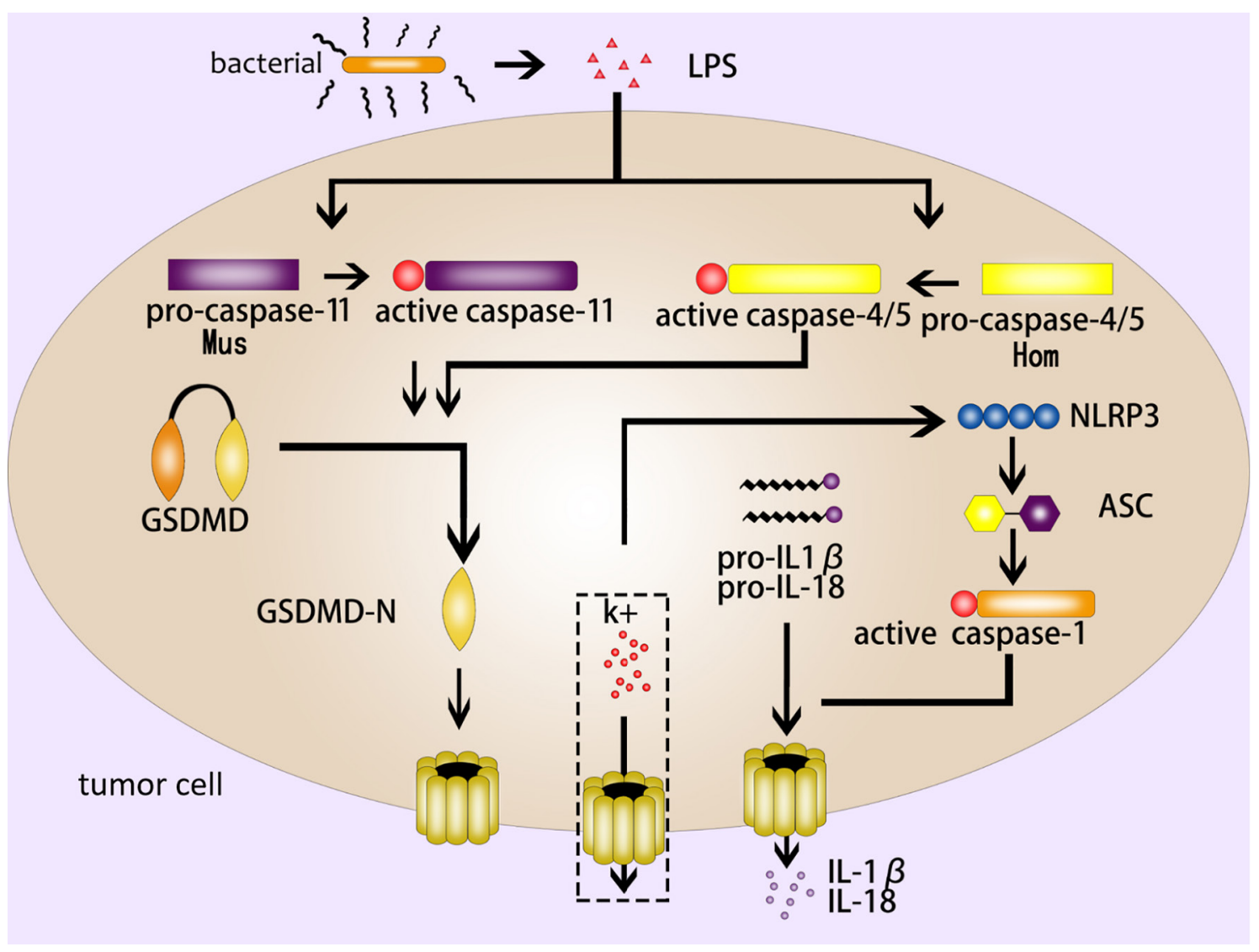

FIGURE 2 | The noncanonical inflammasome pathway. The LPS of gram-negative bacteria activates caspase-11 (mouse) and caspase-4/5 (human), and the active caspase-11/4/5 cleave GSDMD to produce GSDMD-NT to form pores in the cell membrane; NLRP3 is activated by k+ efflux, which activates a series of pyroptosisrelated proteins such as ASC and caspase-1, then caspase-1 induce GSDMD-mediated pyroptosis; IL-1 $\beta$ and IL- 18 are released from the GSDMD pores.

pyroptosis (44) (Figure 3). In addition, it was found that Granzyme B (GZMB) could cleave GSDME like caspase-3 and induce pyroptosis, too (45).

In addition to GSDMD and GSDME proteins, other members of the gasdermin family such as gasdermin $\mathrm{A}$, gasdermin $\mathrm{B}$ and gasdermin $\mathrm{C}$ also play an important role in pore formation and pyroptosis (Figure 4).

GSDMA has only one transcriptional copy in the human genome, while mice have three (Gsdma1-3) (46). GSDMA-NT and Gsdma3-NT have similar effects to GSDMD-NT and GSDME-NT, both of which can bind to cell membrane lipids (cardiolipin or phosphoinositide), and then induce pore formation (11). But how GSDMA is cleaved has not been reported in the literatures yet.

GSDMB has the same site $(17 \mathrm{q} 21.1)$ as GSDMA in human chromosomes $(14,47)$, while the GSDMB gene is not detected in mouse. GSDMB is specifically expressed in the epithelium of the esophagus and gastrointestinal tract, the bronchial epithelium of the asthmatic lung (48). In addition, GSDMB is expressed in liver, neuroendocrine and immune cells, too $(49,50)$. GSDMBNT domain can induce pyroptosis in HEK293T cells (11), and Panganiban et al. found that caspase-1 can cleave full-length
GSDMB at site 236 (51). However, the study by Chao et al. mentions that GSDMB is not a substrate of inflammatory caspases-1/4/5/11 because it lacks specific interdomain junction regions. At the same time, they prove that GSDMB is the substrate of caspase-3/6/7 and mean that the caspase recognition site is the n-terminal domain of GSDMB, not the interdomain junction region (52). Therefore, the complete GSDMB-NT domain cannot be generated by cutting with caspase-3/6/7, and it is not clear whether this cleavage product can induce pyroptosis. Recent studies have found that granzyme A could cleave GSDMB at Lys244, and the GSDMB-NT have pore-forming activity (53). All in all, people are divided on the role of GSDMB in pyroptosis and the mechanism of caspase with GSDMB needs further research.

GSDMC has also been confirmed to play a role in pyroptosis. GSDMC was initially found to be highly expressed in metastatic melanoma cells, and was called MLZE (melanoma-derived leucine zipper-containing extranuclear factor) (54). In the study of Hou et al. it was found that caspase 8 could cleave GSDMC and GSDMC could switch TNF- $\alpha$-induced apoptosis to pyroptosis in MDA-MB-231 breast cancer cells under the death receptor signaling (55). 


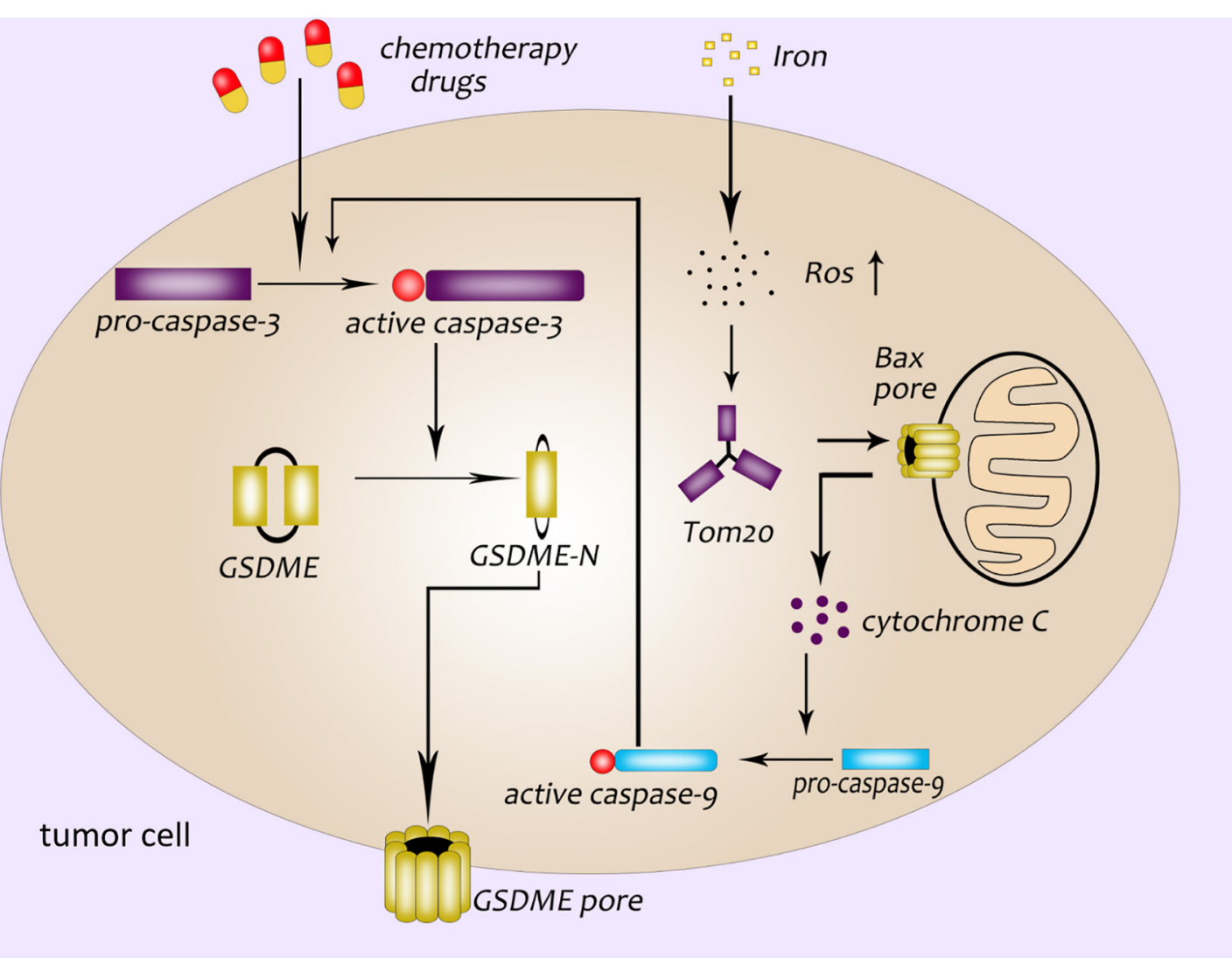

FIGURE 3 | GSDME participates in the pathway of pyroptosis. Chemotherapeutics activate caspase-3; GSDME pore formation in the plasma membrane of cancer cells is dependent on the GSDME-NT cleaved by caspase-3; a newly discovered pyroptosis pathway related to ROS: ROS-Tom20-Bax-cytochrome C-caspase9-caspase3-GSDME.

\section{THE DIFFERENCES AND SIMILARITIES BETWEEN PYROPTOSIS, APOPTOSIS, NECROPTOSIS AND AUTOPHAGY}

We make a table to distinguish them from the definition, basic characteristics and some check indexes (Table 2).

\section{PYROPTOSIS WITH TUMORS}

\section{Lung Cancer and Pyroptosis}

Lung cancer is one of the most harmful malignant tumors in the world. In China, lung cancer deaths account for more than $1 / 5$ of all tumor deaths (70). TP53 was originally a tumor suppressor gene (71-73), and Tianze Zhang et al. found that it had some connections with pyroptosis. In NSCLC(nonsmall-cell lung cancer) tissues, p53 is positively correlated with pyroptosis. In A549 cells, overexpression and silence of p53 can correspondingly regulate the occurrence of pyroptosis, and p53 can induce pyroptosis (74). Gao et al. found that the expression of GSDMD in lung cancer tissues of patients with NSCLC was significantly higher than that in adjacent tissues.
MTT and colony experiments proves that the GSDMDknockout can inhibit the growth of PC9, H1703 and H1975 cell lines of NSCLC (75). Cisplatin and paclitaxel are common chemotherapeutics used to treat tumors (76-78). In the study of Zhang et al., it was found that both cisplatin and paclitaxel could induce apoptosis and pyroptosis of A549 cells, but the effect of cisplatin was strong than taxol (79). The chemotherapeutic drug cisplatin regulates the release of immune factors in the induction of GSDME-mediated pyroptosis, and the level of MIP-1 $\alpha$, MIP$1 \beta$, MIP-2 and IP-10 in tumor tissues and blood are increase. Peng et al. think that it is precisely the release of immune factors that recruits $\mathrm{T}$ cells in tumor tissues and trigger anti-tumor effect (80).

TTM (Trillium tschonoskii Maxim) is a traditional Chinese medicine has anti-tumor effects $(81,82)$. Recent studies have found that PPVI (Polyphyllin VI) extracted from TTM could activate caspase-1 through the ROS/NF- $\mathrm{\kappa B} / \mathrm{NLRP} 3 / \mathrm{GSDMD}$ signaling pathway and turn apoptosis to pyroptosis in NSCLC cells (83). Huaier is also a traditional Chinese medicine have the anti-tumor effects (84). Huaier extract can induce NLRP3mediated pyroptosis and inhibit the development of NSCLC, which provides a new reference idea for clinical treatment about NSCLC (85). 


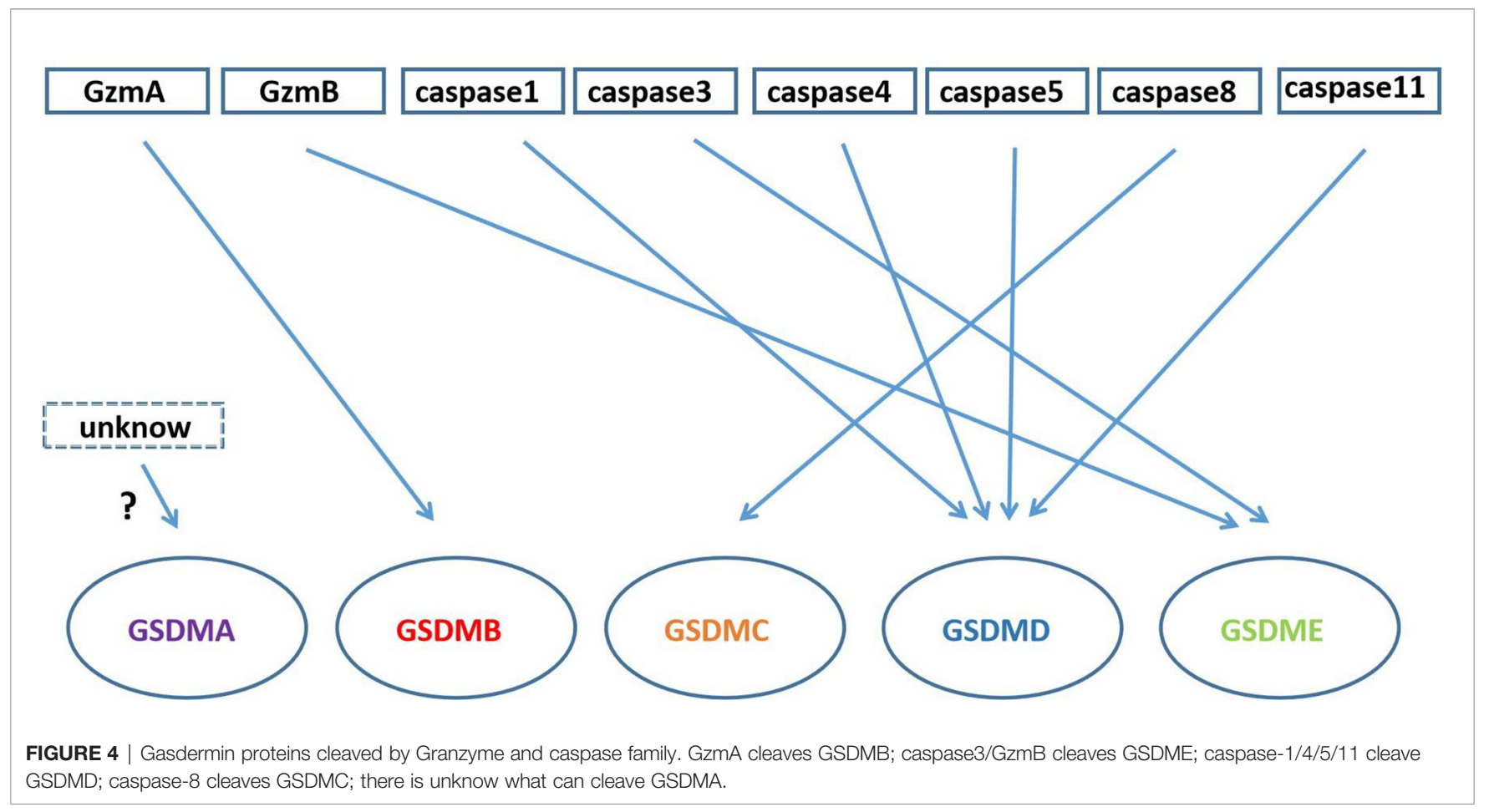

TABLE 2 | The difference and similarities between the four types of death.

\begin{tabular}{|c|c|c|c|c|c|}
\hline & Pyroptosis & Apoptosis & Necroptosis & Autophagy & Refs \\
\hline Definition & $\begin{array}{l}\text { A regulable cell death that relies } \\
\text { on the GSDM protein family to } \\
\text { form pores in the membrane of } \\
\text { the cell. Its occurrence is often the } \\
\text { result of inflammatory Caspase } \\
\text { activation. }\end{array}$ & $\begin{array}{l}\text { One is characterized by } \\
\text { the activation of cysteine } \\
\text { proteases (caspase). The } \\
\text { initiator caspase receives } \\
\text { external or internal } \\
\text { apoptotic signals, and } \\
\text { then activates the } \\
\text { executor caspases to } \\
\text { initiate the death program. }\end{array}$ & $\begin{array}{l}\text { A form of RCD(regulated cell } \\
\text { death), induced by disturbances of } \\
\text { extracellular or intracellular } \\
\text { homeostasis, is heavily dependent } \\
\text { on the MLKL, RIPK1(in some } \\
\text { times), and RIPK3. }\end{array}$ & $\begin{array}{l}\text { A form of RCD } \\
\text { (regulated cell death) } \\
\text { that mechanistically } \\
\text { depends on the } \\
\text { autophagic machinery } \\
\text { (or components } \\
\text { thereof). }\end{array}$ & (13) \\
\hline Inflammation & Yes & no & Yes & no & $(23,57-59)$ \\
\hline $\begin{array}{l}\text { Morphological } \\
\text { characteristic }\end{array}$ & Swell & Shrink & Swell & $\begin{array}{l}\text { Crescent-shaped or } \\
\text { cup-shaped }\end{array}$ & $(60,61)$ \\
\hline Cell membrane & pore formation & Intact & pore formation & Intact & $(58,62,63)$ \\
\hline Organelle & Intact/deformed & intact & Swell & $\begin{array}{l}\text { engulfed by } \\
\text { autophagosomes }\end{array}$ & $(56,58,62)$ \\
\hline Pore-forming protein & gasdermin protein & no & MLKL & no & $(11,63-65)$ \\
\hline IL-18, IL-1 $\beta$ release & Yes & no & Yes & no & $(11,28,62)$ \\
\hline IL-1 $\alpha$ release & Yes & no & Yes & no & $(29,30,62)$ \\
\hline HMGB1 release & Yes & no & Yes & no & $(31,66,67)$ \\
\hline LDH release & Yes & no & Yes & no & $(8,9)$ \\
\hline DNA degradation & Random degradation & Ladder degradation & Random degradation & Random degradation & $(60,64)$ \\
\hline Annexin V/PI staining & $+/+$ & $+/-$ & $+/+$ & $+/-$ & $(68,69)$ \\
\hline
\end{tabular}

\section{Osteosarcoma and Pyroptosis}

Osteosarcoma is a malignant tumor that originates from mesenchymal tissues. It is characterized by malignant spindleshaped stromal cells that can produce bone-like tissue. It is a common primary malignant bone tumor in adolescents (86). The current conventional treatment method is radical surgical resection combined with neoadjuvant chemotherapy (87). Due to the combination of surgical resection and chemotherapy, the 5-year survival rate has been significantly improved (88). However, because of the side effects of chemotherapy drugs, it is still necessary to find new drugs. PG (Emodin 80O- $\beta$-glucopyranoside) is one of the main active components of R. Japonicas, and more and more studies have reported that PG had an important influence on the progression of various malignant tumors $(89,90)$. Osteosarcoma 
cells HOS and SAOS-2 undergo pyroptosis after using PG. At the same time, the anti-tumor effect of PG on HOS and SAOS- 2 cells is mediated by the NLRP3 inflammasome activated by endoplasmic reticulum stress. In addition, in vivo experiments showed that PG reduced the growth and invasion of tumor in osteosarcoma mouse models. These results suggest the possible mechanism of the effect about PG in human osteosarcoma cells and provide a new drug choice for the clinical treatment of osteosarcoma (91).

Dioscin is a kind of steroidal saponins extracted from medicinal plants, including polygonatum, dioscorea nigra and dioscorea zingiberensis (92-94). Recent studies have reported that it also had an inhibitory effect on tumors. Osteosarcoma cells can produce GSDME-NT after being treated with dioscin. Meanwhile, the effect of dioscin in osteosarcoma cells is significantly reduced when GSDME knocked out by the specific siRNA (Small interfering RNA). This study also found that dioscin induced G2/M phase arrest and apoptosis through the JNK/p38 pathway to inhibit the growth of osteosarcoma cells (95). Pyroptosis can trigger cell apoptosis under certain conditions so that the two can work together to exert their anti-osteosarcoma function.

B.-G. TIAN et al. found that miRNA-181a was abnormally elevated in osteosarcoma tissues and cells. In addition, downregulation of miRNA-181a can activate NLRP3-mediated pyroptosis (96). Compared with normal tissues, the expression of GSDMD in osteosarcoma is relatively high, which can independently indicate the prognosis status of patients with osteosarcoma. Rongjin Lin et al. also believe that GSDMD protein may play an important role in the progression and resistance of osteosarcoma (97).

\section{Breast Cancer and Pyroptosis}

Breast cancer is one of the most common malignant tumors that endanger women's health in the world $(98,99)$. Compared with other types of tumors, the incidence of breast cancer is extremely high and shows a trend of increasing and the patients are younger and younger year by year $(98,100)$. In 108 cases of breast cancer and 23 cases of para-carcinoma tissues, Wu et al. detected the expression level of caspase-1, IL-1ßand GSDMD, and they found that the expression of pyroptosis-related proteins were inversely correlated with the tumor grade, tumor size, clinical stage, death risk of breast cancer tissues (101). This also means that proteins like caspase- 1, IL- $1 \beta$ and GSDMD may affect the development and prognosis of breast cancer, providing new molecular targets for the clinically targeted treatment of breast cancer.

DHA (docosahexaenoic acid) is an omega-3 fatty acid with anti-cancer effect. It can inhibit the growth of breast cancer cells, increase apoptosis, and reduce cell invasiveness (102, 103). However, Nathalia et al. added DHA to breast cancer cells MDA-MB-231 and found that the activity of caspase- 1 and GSDMD were enhanced, the secretion of IL-1 $\beta$ was increased, and showed pore-formation activity, which suggesting the occurrence of pyroptosis (104). This discovery provides a new idea for the anti-cancer effect of DHA.

PD-L1 (programmed death ligand 1) on the surface of cancer cells can inhibit anti-tumor immunity by interacting with its receptor PD-1 (programmed cell death protein 1) $(105,106)$. Therefore, blocking the PD-L1/PD-1 interaction can enhance the body's anti-tumor immunity (105). This is a new major breakthrough in cancer treatment $(107,108)$. Studies have reported that PD-L1 was localized on the nuclear (nPD-L1) in breast cancer cells treated with doxorubicin $(109,110)$, but the function and mechanism of nPD-L1 were not yet clear. The study of Hou et al. have showed that under hypoxic condition, PD-L1 could translocate to the nuclear (nPD-L1) through $\mathrm{p}$ Y705-Stat3. What's more, nPD-L1 could switch TNF $\alpha$-induced apoptosis to pyroptosis and GSDMC was cleaved by caspase8 (55). The functionality of a non-immune checkpoint of PD-L1 is clarified here, which is a completely new understanding of PD-L1. At the same time, they also found that some chemotherapeutics such as daunorubicin, doxorubicin, epirubicin and actinomycin D could induce the expression of nPD-L1 (nuclear PD-L1) and GSDMC as well as the activation of caspase-8, inducing pyroptosis in MDAMB-231 human breast cancer cells (55).

\section{Hepatocellular Carcinoma and Pyroptosis}

HCC (hepatocellular carcinoma) has the sixth highest incidence rate in the global cancer incidence rate and the second highest mortality rate in the global cancer mortality rate (111). HCC patients in China account for about $55 \%$ of new HCC cases worldwide each year (112). The main clinical treatments for liver cancer include chemotherapy, radiotherapy, surgical resection and interventional therapy, but chemotherapy and radiotherapy have certain side effects (113).

Recently, it has been reported that the induction of pyroptosis of HCC cells can inhibit the growth of liver cancer (114). Wei et al. found that the expression of NLRP3 and ASC, the components of the NLRP3 inflammasome, were significantly lower than that of paracancer tissues. The expression of NLRP3 was significantly down-regulated when HCC. With the development of the pathological grade and clinical stage of HCC patients, the expression of inflammatory components of NLRP3 are decreased (115). Later, they found that the E2 (17 $\beta$ estradiol)-induced death of HCC cells was related to caspase1mediated pyroptosis, and proved that NLRP3 inflammasome inhibited autophagy through the E2/ER $\beta / A M P K / m T O R$ pathway (116). E2 induces pyroptosis and inhibits autophagy, which significantly slows down the development of HCC.

AIF (Alpinumisoflavone) is the principal bioactive component of derriseriocarpa sourced from China that has the effects of anti-tumor $(117,118)$. For liver cancer, Zhang et al. found that AIF could also inhibit the growth and metastasis of HCC cells by inducing NLRP3-mediated pyroptosis. In vivo experiments, they found that AIF could inhibit tumor growth and increase the expression of pyroptosis-related proteins in tumor tissues (114). Euxanthone is a flavonoid isolated from the Polygala Caudata plant. It was used as a traditional Chinese medicine to treat coughs in ancient China (119). Recent studies have shown that it has antitumor effects $(120,121)$. Chen et al. collected samples from hospital patients and found that the expression of caspase-1, IL$1 \beta$ and IL-18 were low in both HCC tissues and HCC cell lines. At the same time, they found that Euxanthone could inhibit the development of HCC by inducing pyroptosis (122). 


\section{Gastric Cancer and Pyroptosis}

Gastric cancer is one of the common malignant tumors (123). Among the malignant tumors surveyed in 2018, the incidence and mortality of gastric cancer ranked fifth and second. Early gastric cancer is difficult to detect, $80 \%$ of patients are in the middle and advanced stages when they see a doctor, and the 5year survival rate is only about $30 \%$ (124). Chemotherapy drugs are often used to treat the gastric cancer, but the mechanism is still unclear. Studies have found that there is a certain relationship between gastric cancer and pyroptosis (125).

Wang et al. found that gastric cancer cell lines SGC-7901 and MKN-45 underwent pyroptosis when treated with 5-FU(5fluorouracil), and they proved that caspase- 3 was activated by 5-FU to induce GSDME-mediated pyroptosis (126). The same gastric cancer cell line SGC-7901 showed obvious pyroptosis characteristics after using BIX-01294 combined with cisplatin. And GSDME-knockout could convert the pyroptosis into apoptosis under the same condition (127).

In gastric cancer tissues, the expression of GSDMD was lower than normal. Studies have found that downregulating the expression of GSDMD could promote the development of gastric cancer. At the meanwhile, Wang et al. speculated that the downregulation of GSDMD may regulate cell cycle-related proteins by activating ERK (extraCellular signal-regulated kinase), STAT3 (Signal Transducer and Activator of Transcription 3) and PI3K/AKT (phosphatidylinositol 3 kinase) signaling pathway, and promoted the S/G2 transition of gastric cancer cells. Therefore, GSDMD has certain clinical significance in the targeted therapy and diagnosis of gastric cancer (128).

\section{Other Types of Cancer and Pyroptosis}

Nobiletin is a food phytochemical extracted from citrus fruits (129). It has been reported that it could inhibit the growth of ovarian cancer $(130,131)$. Zhang et al. found that nobiletin could reduce the mitochondrial membrane potential, induce ROS generation, and play a role in GSDMD/GSDME-mediated pyroptosis in HOCC (human ovarian cancer cells). In summary, nobiletin may become a new anti-ovarian cancer drug, which can trigger apoptosis and induce pyroptosis by regulating the autophagy of ovarian cancer cells (132).

ESCC (esophageal squamous cell carcinoma) is a kind of gastrointestinal cancer. Due to the resistance of cancer cells to chemotherapy drugs such as cisplatin and 5-fluorouracil, therapeutic effects are often unsatisfactory (133). Metformin is a kind of anti-diabetic drug (134). A study reported that metformin could induce GSDMD-mediated pyroptosis of ESCC by targeting the miR-497/PELP1 axis (135).

In addition, $\mathrm{Yu}$ et al. found that the expression of miR-214 and NLRP3 were down-regulated in cervical cancer patients, while the up-regulation of miR-214 could promote the pyroptosis of cervical cancer cells by targeting the expression of NLRP3 (136).

Endometrial cancer is one of the most common cancers in gynecology (137). Studies have reported that pyroptosis-related protein caspase-1, NLRP3 and GSDMD were highly expressed in endometrial cancer tissue, and hydrogen could inhibit the growth of endometrial cancer by inducing GSDMD-mediated pyroptosis through a ROS/NLRP3/caspase-1 pathway (138).
PDAC(Pancreatic ductal adenocarcinoma) accounts for 95\% of pancreatic malignancies. Despite decades of effects, its fiveyear survival rate is still only about $8 \%$ and the incidence is increasing year by year (139). The expression of MST1 (STE20like kinase 1) in PDAC is decreased. Restoring the expression of MST1 can promote PDAC cell death, and inhibit the proliferation, migration and invasion of PDAC cells by inducing caspase-1-mediated pyroptosis via ROS (140).

Because colitis is one of the risk factors in colorectal cancer, CAC (colitis-associated colorectal cancer) accounts for about 5\% of colorectal cancer cases (141). CAC is one of the examples of chronic inflammation related cancers and chronic inflammation is present in the early stage of tumor onset (142). It has been found that GSDME-mediated pyroptosis induced cancer cells proliferation and PCNA(proliferating cell nuclear antigen) expression through the ERK1/2 pathway by releasing intracellular HMGB1, which in turn promoted the development of CAC (143). The results of the study emphasize the new role of HMGB1 in promoting the tumorigenesis of CAC, so it may become a new strategy to inhibit GSDME-mediated pyroptosis or use neutralizing anti-HMGB1 antibodies in the treatment of CAC.

The small molecule inhibitors of serine dipeptidase DPP8 and DPP9 can induce pyroptosis in mouse and human monocytes/ macrophages $(144,145)$. Johnson et al. found that CARD8 (caspase activation and recruitment domain) can regulate procaspase-1-mediated-pyroptosis in human myeloid cells induced by the inhibitor DPP8/9. Further studies have shown that DPP8/ 9 inhibitors-induced pyroptosis in most human AML (acute myeloid leukemia) cell lines and primary AML samples, and these inhibitors also have effects on inhibiting human AML in mouse models (146) (Table 3).

\section{ANTITUMOR IMMUNITY}

Pyroptosis in tumor cells can induce antitumor immunity (147150). In GSDME-expressing tumor cells, the damage-associated molecular patterns (DAMPs) generated by the pyroptosis of the cells can recruit immune cells to the tumor microenvironment and enhance their immunity. The expression of GSDME greatly increases the number of TILs (tumor infiltrating lymphocytes) and the phagocytic capacity of macrophages (151).

Granzyme B has the same cleavage site as caspase- 3 in NK cells, which can cleave GSDME to induce pyroptosis (45). Due to the occurrence of pyroptosis, it further promotes antitumor immunity and inhibits tumor growth. In immunodeficient mice and mice lacking NK cells and CD8+ killer T cells, the inhibitory effect of GSDME on tumors disappeared, indicating that this inhibitory effect depends on these two killer cells in the immune system (45). Cytotoxic lymphocytes [such as CTL (Cytotoxic T Lymphocyte) cells and NK cells] are important effector cells of the immune system. They release perforin and other mediators to play a killing role after recognizing target cells $(152,153)$. At present, the killing effect of lymphocytes is still generally considered to trigger apoptosis on target cells (154). However, Zhou et al. found that Granzyme A could enter tumor cells via perforin and induce 
TABLE 3 | Tumors and pyroptosis.

\begin{tabular}{|c|c|c|}
\hline Tumor types & Discovery & Refs \\
\hline Lung cancer & $\begin{array}{l}\text { 1. p53 can induce pyroptosis (Gao et al.); } \\
\text { 2. chemotherapeutic drug cisplatin can indue GSDME-mediated pyroptosis (Peng et al.); } \\
\text { 3. PPVI can active caspase-1 and turn apoptosis to pyroptosis of NSCLC cells through the ROS/NF-אB/NLRP3/GSDMD } \\
\text { pathway (Teng JF et al.); } \\
\text { 4. Huaier extract can activate NLRP3 to induce pyroptosis and inhibit the development of NSCLC (Xie Jet al.). }\end{array}$ & $\begin{array}{c}(74,75, \\
80,83,85)\end{array}$ \\
\hline Osteosarcoma & $\begin{array}{l}\text { 1. PG (Emodin } 800-\beta \text {-glucopyranoside) can reduce tumor growth and invasion in osteosarcoma mouse models by inducing } \\
\text { pyroptosis (Tian B et al.); } \\
\text { 2. Dioscin can induce GSDME-mediated pyroptosis in osteosarcoma cells (Ding Q et al.); } \\
\text { 3. MiRNA-181a is abnormally elevated in osteosarcoma tissues and cells and the down-regulation of miRNA-181a can } \\
\text { induce NLRP3-mediated pyroptosis (B.-G. TIAN et al.); } \\
\text { 4. The expression of GSDMD is relatively high in osteosarcoma tissues compared to normal (Rongjin Lin et al.). }\end{array}$ & $\begin{array}{l}(91,95- \\
97)\end{array}$ \\
\hline Breast cancer & $\begin{array}{l}\text { 1. Pyroptosis-related protein such as caspase-1, IL-1 } \beta \text {, and Gasdermin-D are negatively correlated with the tumor grade, } \\
\text { tumor size, clinical stage, death risk of breast cancer (Wu et al.); } \\
\text { 2. DHA (docosahexaenoic acid) can induce GSDMD-mediated pyroptosis of breast cancer cells (Nathalia et al.); } \\
\text { 3. Under hypoxic condition, nPD-L1 can switch TNF } \alpha \text {-induced apoptosis to pyroptosis and GSDMC is cleaved by caspase } 8 \\
\text { in breast cancer cells (Hou et al.). }\end{array}$ & $\begin{array}{l}(55,101, \\
104)\end{array}$ \\
\hline Hepatocellular carcinoma & $\begin{array}{l}\text { 1. The expression of NLRP3 and ASC in HCC tissues were significantly lower than paracancer tissues (Wei et al.); } \\
\text { 2. NLRP3 inflammasomes induce pyroptosis and inhibit autophagy through the E2/ERB/AMPK/mTOR pathway (Wei et al.); } \\
\text { 3. AIF can inhibit the growth of HCC both in vitro and in vivo by inducing NLRP3-mediated pyroptosis (Zhang et al.); } \\
\text { 4. Euxanthone can inhibit the development of HCC by inducing pyroptosis (Chen et al.). }\end{array}$ & $\begin{array}{l}(114-116, \\
122)\end{array}$ \\
\hline Gastric cancer & $\begin{array}{l}\text { 1. Caspase-3 was activated by } 5 \text {-FU to induce GSDME-mediated pyroptosis in gastric cancer cell lines SGC-7901 and MKN- } \\
45 \text { (Wang et al.); } \\
\text { 2. Knocking out GSDME in SGC-7901 cells can convert the pyroptosis into apoptosis after using BIX-01294 combined with } \\
\text { cisplatin (Deng BB et al.); } \\
\text { 3. The expression of GSDMD in gastric cancer is lower than normal tissues (Wang et al.); } \\
\text { 4. A speculation that the downregulation of GSDMD may regulate cell cycle-related proteins by activating ERK, STAT3 and } \\
\text { PI3K/AKT pathway, and promote the S/G2 transition of gastric cancer cells (Wang et al.). }\end{array}$ & $(126-128)$ \\
\hline Ovarian cancer & $\begin{array}{l}\text { Nobiletin can trigger apoptosis and induce GSDMD/GSDME-mediated pyroptosis by regulating the autophagy of ovarian } \\
\text { cancer cells (Zhang et al.). }\end{array}$ & $(132)$ \\
\hline $\begin{array}{l}\text { ESCC (Esophageal } \\
\text { squamous cell carcinoma) }\end{array}$ & Metformin can induce GSDMD-mediated pyroptosis of ESCC by targeting the miR-497/PELP1 axis (Lu Wang et al.). & $(135)$ \\
\hline Cervical cancer & $\begin{array}{l}\text { The up-regulation of miR-214 can promote the pyroptosis of cervical cancer cells by targeting the expression of NLRP3 } \\
\text { (Yu et al.). }\end{array}$ & $(136)$ \\
\hline Endometrial cancer & $\begin{array}{l}\text { Hydrogen can inhibit the development of endometrial cancer by induce GSDMD-mediated pyroptosis through a ROS/NLRP3/ } \\
\text { caspase-1 pathway (Ye Yang et al.). }\end{array}$ & $(138)$ \\
\hline $\begin{array}{l}\text { PDAC (Pancreatic ductal } \\
\text { adenocarcinoma) }\end{array}$ & $\begin{array}{l}\text { The expression of MST1 in PDAC is decreased and overexpression of MST1 can promote PDAC cell death by inducing } \\
\text { caspase-1-mediated pyroptosis via ROS (Cui et al.). }\end{array}$ & $(140)$ \\
\hline $\begin{array}{l}\text { CAC (colitis-associated } \\
\text { colorectal cancer) }\end{array}$ & $\begin{array}{l}\text { GSDME-mediated pyroptosis can induce cancer cells proliferation and PCNA expression through the ERK1/2 pathway by } \\
\text { releasing intracellular HMGB1 (Tan et al.). }\end{array}$ & $(143)$ \\
\hline $\begin{array}{l}\text { AML (acute myeloid } \\
\text { leukemia) }\end{array}$ & $\begin{array}{l}\text { DPP8/9 inhibitors-induced pyroptosis in most human AML cell lines and primary AML samples, and these inhibitors also have } \\
\text { an effect on inhibiting human AML in mouse models (Johnson et al.). }\end{array}$ & $(146)$ \\
\hline
\end{tabular}

GSDMB-mediated pyroptosis. Then up-regulating the expression of GSDMB can promote pyroptosis (53).

GSDMB is highly expressed in tumor cells derived from epithelial cells of the digestive system and GSDMB-mediated pyroptosis can enhance the antitumor immunity. This phenomenon also explains the killing mechanism of cytotoxic lymphocytes from some perspectives. In addition, Wang et al. used the bioorthogonal system to reveal that a small number of tumor cells undergo pyroptosis, which is sufficient to effectively regulate the tumor immune microenvironment, thereby activating a strong T cell-mediated antitumor immune response (155). This discovery provides a new idea for the research and development of tumor immunotherapy drugs. Gasdermin family proteins also have become potential biomarkers for tumor immunotherapy. The stimulus of gasdermin proteins is likely to become a new direction for the development of antitumor drugs.

CAR-T (chimeric antigen receptor $\mathrm{T}$ cell) immunotherapy is a new type of targeted therapy for the treatment of hematologic malignancies (156-159). In recent years, good results have been achieved in the CAR-T immunotherapy. But CRS (cytokine release syndrome) is an important side effect of CAR-T therapy (160-162), and the mechanism of CRS is not yet clear. Liu et al. found that CAR-T cells released granzyme B, which activated caspase- 3 and then cleaved GSDME or cleaved GSDME directly to cause pyroptosis (163) (Figure 5). Studies have showed that GSDME-knockout in tumor cells could eliminate CRS, which provided a new reference for reducing CRS after using CAR-T therapy clinically.

\section{CONCLUSION}

Pyroptosis is a new type of PCD. Its induction depends on the gasdermin protein family and is often activated by caspase (164). GSDMD and GSDME of the gasdermin protein family are the most common types in the research. GSDMD is related to the 


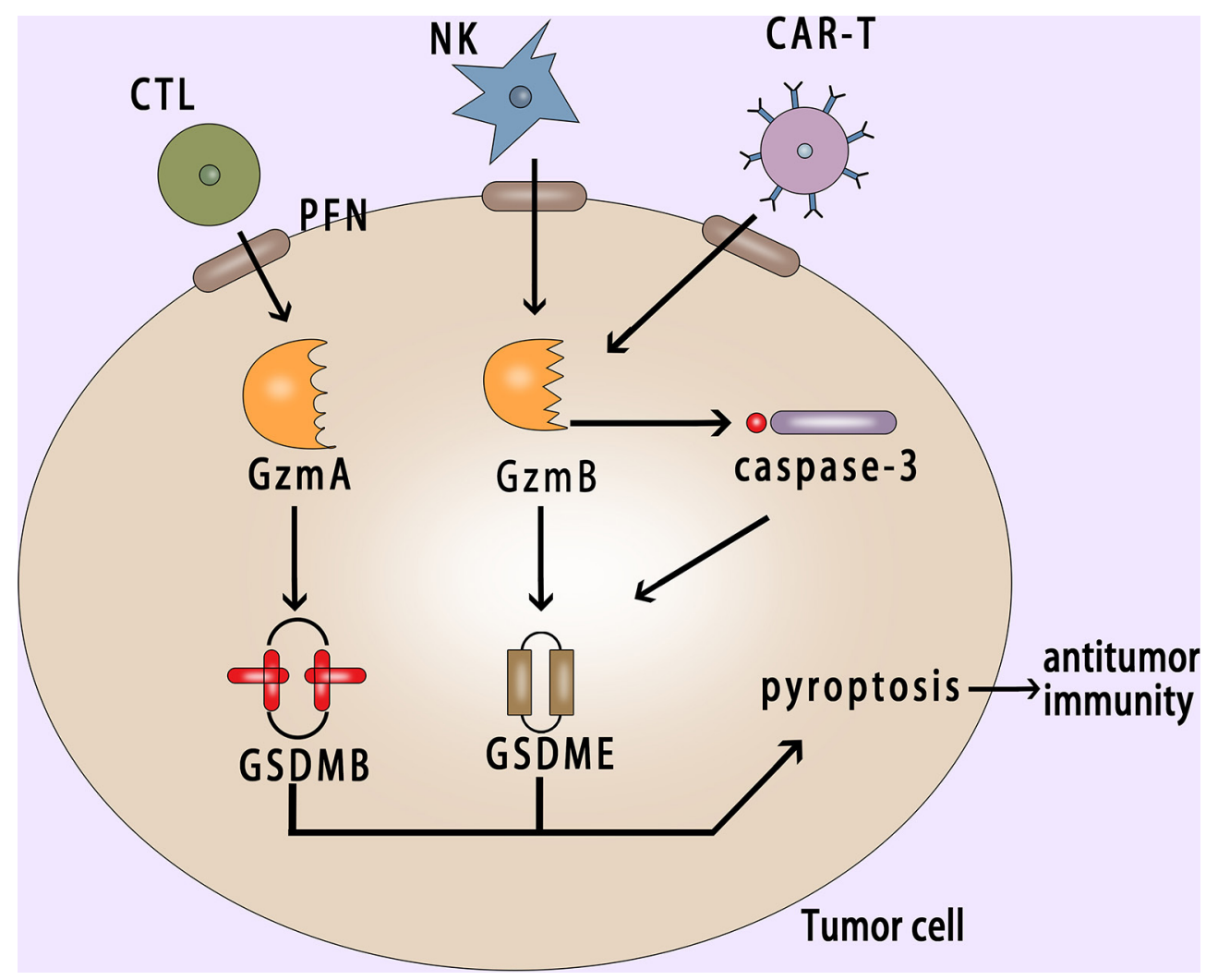

FIGURE 5 | Pyroptosis in cancer cell activates antitumor immunity. GzmA and GzmB released by CTL and NK cells with the help of perforin enter into the cancer cell and induce the GSDMB-mediated and GSDME-mediated pyroptosis respectively; CAR-T cells release granzyme B, which can activate caspase-3 or cleave GSDME directly to induce pyroptosis; Pyroptosis can suppress tumor growth and promote antitumor immunity. PFN, perforin; NK, natural killer; CAR-T, chimeric antigen receptor $\mathrm{T}$ cell.

canonical and noncanonical pathway of pyroptosis. In addition, the gasdermin protein family includes GSDMA, GSDMB, GSDMC and Pejvakin, too. Except for the Pejvakin protein, the others all have the function of pore-formation $(165,166)$.

Recent researches have found that pyroptosis was related to many types of diseases, such as cardiovascular diseases, metabolic diseases, immune-related diseases and cancers (167-170). Cancer is very harmful to human health and the current treatments for cancer are limited. Apoptosis-induction in tumor cells is a common way in clinical treatment of tumors (43). Due to the anti-apoptotic effect of tumor cells, pyroptosis, a new cell death way, has great potential in the treatment of tumors. There are many reports showed that some drugs can induce pyroptosis in tumor cells and these drugs can inhibit tumor growth in vivo experiments, too. The expression of pyroptosis-related proteins such as gasdermin family, caspase family, NLRP3, ASC, etc. are mostly different between tumor tissues and normal tissues. These protein molecules may become new targets for tumor progression and treatment.

It is a recent discovery that pyroptosis can induce antitumor immunity $(45,149)$. If we can utilize tumor pyroptosis to stimulate a stronger immune function in the body, this may become another major advancement in tumor treatment.
At present, people's understanding about pyroptosis is still superficial. And the mechanism of pyroptosis is still needs us to explore, more experiments and clinical trials are needed to explore its actual value and clinical application.

\section{AUTHOR CONTRIBUTIONS}

DW and CW drafted the manuscript. DW, YL, XY, and SZ discussed and revised the manuscript. SZ designed the research. All authors contributed to the article and approved the submitted version.

\section{FUNDING}

This work was funded by the Guangxi Science and Technology Research Base and Talent-specific Project (AD18126021); National Science and Technology Major Project for New Drug Innovation (2018ZX09733001-004-002); National Natural Science Foundation of China (NSFC) project (No. 81872491); Key Laboratory of the Ministry of Education Project for Early Prevention and Treatment of Regional High-risk Tumors (GKE2018-03, GKE2019-09, GKE-ZZ202007). 


\section{REFERENCES}

1. Torre LA, Bray F, Siegel RL, Ferlay J, Lortet-Tieulent J, Jemal A. Global Cancer Statistics, 2012. CA Cancer J Clin (2015) 65(2):87-108. doi: 10.3322/ caac. 21262

2. Fang Y, Tian S, Pan Y, Li W, Wang Q, Tang Y, et al. Pyroptosis: A New Frontier in Cancer. BioMed Pharmacother (2020) 121:109595. doi: 10.1016/ j.biopha.2019.109595

3. FriedlanderAM. Macrophages Are Sensitive to Anthrax Lethal Toxin Through an Acid-Dependent Proces. J Biol Chem (1986) 261(16):7123-6. doi: 10.1016/S0021-9258(17)38364-3

4. Zychlinsky A, PrevostMC, Sansonetti PJ. Shigella Flexneri Induces Apoptosis in Infected Macrophages. Nature (1992) 358(6382):167-9. doi: $10.1038 / 358167 \mathrm{a} 0$

5. Hersh D, Monack DM, Smith MR, Ghori N, Falkow S. A Zychlinsky. The Salmonella Invasin SipB Induces Macrophage Apoptosis by Binding to Caspase-1. Proc Natl Acad Sci USA (1999) 96(5):2396-401. doi: 10.1073/ pnas.96.5.2396

6. Cookson BT, Brennan M. Pro-Inflammatory Programmed Cell Death. Trends Microbiol (2001) 9(3):113-4. doi: 10.1016/s0966-842x(00)01936-3

7. Fink SL, Cookson BT. Apoptosis, Pyroptosis, and Necrosis: Mechanistic Description of Dead and Dying Eukaryotic Cells. Infect Immun (2005) 73 (4):1907-16. doi: 10.1128/IAI.73.4.1907-1916.2005

8. Shi J, Zhao Y, Wang K, Shi X, Wang Y, Huang H, et al. Cleavage of GSDMD by Inflammatory Caspases Determines Pyroptotic Cell Death. Nature (2015) 526(7575):660-5. doi: 10.1038/nature15514

9. Kayagaki N, Stowe IB, Lee BL, O’Rourke K, Anderson K, Warming S, et al. Caspase-11 Cleaves Gasdermin D for non-Canonical Inflammasome Signalling. Nature (2015) 526(7575):666-71. doi: 10.1038/nature15541

10. Liu X, Zhang Z, Ruan J, Pan Y, Magupalli VG, Wu H, et al. Inflammasome-Activated Gasdermin D Causes Pyroptosis by Forming Membrane Pores. Nature (2016) 535(7610):153-8. doi: 10.1038/ nature 18629

11. Ding J, Wang K, Liu W, She Y, Sun Q, Shi J, et al. Pore-Forming Activity and Structural Autoinhibition of the Gasdermin Family. Nature (2016) 535 (7610):111-6. doi: 10.1038/nature18590

12. Shi J, Gao W, Shao F. Pyroptosis: Gasdermin-Mediated Programmed Necrotic Cell Death. Trends Biochem Sci (2017) 42(4):245-54. doi: 10.1016/j.tibs.2016.10.004

13. Galluzzi L, Vitale I, Aaronson SA, Abrams JM, Adam D, Agostinis P, et al. Molecular Mechanisms of Cell Death: Recommendations of the Nomenclature Committee on Cell Death 2018. Cell Death Differ (2018) 25 (3):486-541. doi: 10.1038/s41418-017-0012-4

14. Saeki N, Kuwahara Y, Sasaki H, Satoh H, Shiroishi T. Gasdermin (Gsdm) Localizing to Mouse Chromosome 11 is Predominantly Expressed in Upper Gastrointestinal Tract But Significantly Suppressed in Human Gastric Cancer Cells. Mamm Genome (2000) 11(9):718-24. doi: 10.1007/ s003350010138

15. Jorgensen I, Rayamajhi M, Miao EA. Programmed Cell Death as a Defence Against Infection. Nat Rev Immunol (2017) 17(3):151-64. doi: 10.1038/ nri.2016.147

16. Martinon F, Burns K, Tschopp Jürg. The Inflammasome: A Molecular Platform Triggering Activation of Inflammatory Caspases and Processing of proIL-Beta. Mol Cell Oncol (2002) 10(2):417-26. doi: 10.1016/s1097-2765 (02)00599-3

17. Latz E, Xiao TS, Stutz A. Activation and Regulation of the Inflammasomes. Nat Rev Immunol (2013) 13(6):397-411. doi: 10.1038/nri3452

18. Mariathasan S, Newton K, Monack DM, Vucic D, French DM, Lee WP, et al. Differential Activation of the Inflammasome by Caspase-1 Adaptors ASC and Ipaf. Nature (2004) 430(6996):213-8. doi: 10.1038/ nature 02664

19. Hornung V, Ablasser A, Charrel-Dennis M, Bauernfeind F, Horvath G, Caffrey DR, et al. AIM2 Recognizes Cytosolic dsDNA and Forms a Caspase1-Activating Inflammasome With ASC. Nature (2009) 458(7237):514-8. doi: 10.1038 /nature 07725

20. Fernandes-Alnemri T, Yu JW, Datta P, Wu J, Alnemri ES. AIM2 Activates the Inflammasome and Cell Death in Response to Cytoplasmic DNA. Nature (2009) 458(7237):509-13. doi: 10.1038/nature07710
21. Roberts TL, Idris A, Dunn JA, Kelly GM, Burnton CM, Hodgson S, et al. HIN-200 Proteins Regulate Caspase Activation in Response to Foreign Cytoplasmic DNA. Science (2009) 323(5917):1057-60. doi: 10.1126/ science.1169841

22. Masters SL, Lagou V, Jéru I, Baker PJ, Van Eyck L, Parry DA, et al. Familial Autoinflammation With Neutrophilic Dermatosis Reveals a Regulatory Mechanism of Pyrin Activation. Sci Transl Med (2016) 8(332):332ra345 doi: 10.1126/scitranslmed.aaf1471

23. Rathinam VA, Fitzgerald KA. Inflammasome Complexes: Emerging Mechanisms and Effector Functions. Cell (2016) 165(4):792-800. doi: 10.1016/j.cell.2016.03.046

24. He Y, Hara H, Nunez G. Mechanism and Regulation of NLRP3 Inflammasome Activation. Trends Biochem Sci (2016) 41(12):1012-21. doi: 10.1016/j.tibs.2016.09.002

25. Srinivasula SM, Poyet JL, Razmara M, Datta P, Zhang Z, Alnemri ES. The PYRIN-CARD Protein ASC Is an Activating Adaptor for Caspase-1. J Biol Chem (2002) 277(24):21119-22. doi: 10.1074/jbc.C200179200

26. Van Opdenbosch N, Lamkanfi M. Caspases in Cell Death, Inflammation, and Disease. Immunity (2019) 50(6):1352-64. doi: 10.1016/j.immuni. 2019.05.020

27. Case CL, Roy CR. Asc Modulates the Function of NLRC4 in Response to Infection of Macrophages by Legionella Pneumophila. mBio (2011) 2(4): e00117-11. doi: 10.1128/mBio.00117-11

28. Lacey CA, Mitchell WJ, Dadelahi AS, Skyberg JA. Caspase-1 and Caspase-11 Mediate Pyroptosis, Inflammation, and Control of Brucella Joint Infection. Infect Immun (2018) 86(9):e00361-18. doi: 10.1128/IAI.00361-18

29. Tsuchiya K, Hosojima S, Hara H, Kushiyama H, Mahib MR, Kinoshita T, et al. Gasdermin D Mediates the Maturation and Release of IL-1alpha Downstream of Inflammasomes. Cell Rep (2021) 34(12):108887. doi: 10.1016/j.celrep.2021.108887

30. Xia S, Zhang Z, Magupalli VG, Pablo JL, Dong Y, Vora SM, et al. Gasdermin D Pore Structure Reveals Preferential Release of Mature Interleukin-1. Nature (2021) 593(7860):607-11. doi: 10.1038/s41586-021-03478-3

31. Volchuk A, Ye A, Chi L, Steinberg BE, Goldenberg NM. Indirect Regulation of HMGB1 Release by Gasdermin D. Nat Commun (2020) 11(1):4561. doi: 10.1038/s41467-020-18443-3

32. Yang D, He Y, Munoz-Planillo R, Liu Q, Nunez G. Caspase-11 Requires the Pannexin-1 Channel and the Purinergic P2X7 Pore to Mediate Pyroptosis and Endotoxic Shock. Immunity (2015) 43(5):923-32. doi: 10.1016/ j.immuni.2015.10.009

33. Kayagaki N, Warming S, Lamkanfi M, Vande Walle L, Louie S, Dong J, et al Non-Canonical Inflammasome Activation Targets Caspase-11. Nature (2011) 479(7371):117-21. doi: 10.1038/nature10558

34. Chekeni FB, Elliott MR, Sandilos JK, Walk SF, Kinchen JM, Lazarowski ER, et al. Pannexin 1 Channels Mediate 'Find-Me' Signal Release and Membrane Permeability During Apoptosis. Nature (2010) 467(7317):863-7. doi: $10.1038 /$ nature 09413

35. Munoz-Planillo R, Kuffa P, Martinez-Colon G, Smith BL, Rajendiran TM, Nunez G. K(+) Efflux Is the Common Trigger of NLRP3 Inflammasome Activation by Bacterial Toxins and Particulate Matter. Immunity (2013) 38 (6):1142-53. doi: 10.1016/j.immuni.2013.05.016

36. Ruhl S, Broz P. Caspase-11 Activates a Canonical NLRP3 Inflammasome by Promoting K(+) Efflux. Eur J Immunol (2015) 45(10):2927-36. doi: 10.1002/ eji.201545772

37. Shi J, Zhao Y, Wang Y, Gao W, Ding J, Li P, et al. Inflammatory Caspases Are Innate Immune Receptors for Intracellular LPS. Nature (2014) 514 (7521):187-92. doi: 10.1038/nature13683

38. Croes L, Beyens M, Fransen E, Ibrahim J, Vanden Berghe W, Suls A, et al. Large-Scale Analysis of DFNA5 Methylation Reveals Its Potential as Biomarker for Breast Cancer. Clin Epigenetics (2018) 10:51. doi: 10.1186/ s13148-018-0479-y

39. Rogers C, Fernandes-Alnemri T, Mayes L, Alnemri D, Cingolani G, Alnemri ES. Cleavage of DFNA5 by Caspase-3 During Apoptosis Mediates Progression to Secondary Necrotic/Pyroptotic Cell Death. Nat Commun (2017) 8:14128. doi: 10.1038/ncomms14128

40. Wang Y, Gao W, Shi X, Ding J, Liu W, He H, et al. Chemotherapy Drugs Induce Pyroptosis Through Caspase-3 Cleavage of a Gasdermin. Nature (2017) 547(7661):99-103. doi: 10.1038/nature22393 
41. FleisherTA. Apoptosis. Ann Allergy Asthma Immunol (1997) 78(3):245-9. doi: 10.1016/S1081-1206(10)63176-6

42. Van Cruchten S, BroeckWVD. Morphological and Biochemical Aspects of Apoptosis, Oncosis and Necrosis. Anat Histol Embryol (2002) 31(4):214-23. doi: 10.1046/j.1439-0264.2002.00398.x

43. Pistritto G, Trisciuoglio D, Ceci C, Garufi A, D’Orazi G. Apoptosis as Anticancer Mechanism Function and Dysfunction of Its Modulators and Targeted Therapeutic Strategies. Aging (Albany NY) (2016) 8(4):603-19. doi: 10.18632/aging.100934

44. Zhou B, Zhang JY, Liu XS, Chen HZ, Ai YL, Cheng K, et al. Tom20 Senses Iron-Activated ROS Signaling to Promote Melanoma Cell Pyroptosis. Cell Res (2018) 28(12):1171-85. doi: 10.1038/s41422-018-0090-y

45. Zhang Z, Zhang Y, Xia S, Kong Q, Li S, Liu X, et al. Gasdermin E Suppresses Tumour Growth by Activating Anti-Tumour Immunity. Nature (2020) 579 (7799):415-20. doi: 10.1038/s41586-020-2071-9

46. Runkel F, Marquardt A, Stoeger C, Kochmann E, Simon D, Kohnke B, et al. The Dominant Alopecia Phenotypes Bareskin, Rex-Denuded, and Reduced Coat 2 Are Caused by Mutations in Gasdermin 3. Genomics (2004) 84 (5):824-35. doi: 10.1016/j.ygeno.2004.07.003

47. Katoh M, Katoh M. Evolutionary Recombination Hotspot Around GSDMLGSDM Locus Is Closely Linked to the Oncogenomic Recombination Hotspot Around the PPP1R1B-ERBB2-GRB7 Amplicon. Int $J$ Oncol (2004) 24(4):757-63. doi: 10.3892/ijo.24.4.757

48. Das S, Miller M, Beppu AK, Mueller J, McGeough MD, Vuong C, et al. GSDMB Induces an Asthma Phenotype Characterized by Increased Airway Responsiveness and Remodeling Without Lung Inflammation. Proc Natl Acad Sci USA (2016) 113(46):13132-7. doi: 10.1073/pnas.1610433113

49. Hu Y, Jin S, Cheng L, Liu G, Jiang Q. Autoimmune Disease Variants Regulate GSDMB Gene Expression in Human Immune Cells and Whole Blood. Proc Natl Acad Sci USA (2017) 114(38):E7860-2. doi: 10.1073/ pnas. 1712127114

50. Carl-McGrath S, Schneider-Stock R, Ebert M, Rocken C. Differential Expression and Localisation of Gasdermin-Like (GSDML), a Novel Member of the Cancer-Associated GSDMDC Protein Family, in Neoplastic and Non-Neoplastic Gastric, Hepatic, and Colon Tissues. Pathology (2008) 40(1):13-24. doi: 10.1080/00313020701716250

51. Panganiban RA, Sun M, Dahlin A, Park HR, Kan M, Himes BE, et al. A Functional Splice Variant Associated With Decreased Asthma Risk Abolishes the Ability of Gasdermin B to Induce Epithelial Cell Pyroptosis. J Allergy Clin Immunol (2018) 142(5):1469-1478 e1462. doi: 10.1016/ j.jaci.2017.11.040

52. Chao KL, Kulakova L, Herzberg O. Gene Polymorphism Linked to Increased Asthma and IBD Risk Alters Gasdermin-B Structure, a Sulfatide and Phosphoinositide Binding Protein. Proc Natl Acad Sci USA (2017) 114(7): E1128-37. doi: 10.1073/pnas.1616783114

53. Zhou Z, He H, Wang K, Shi X, Wang Y, Su Ya, et al. Granzyme A From Cytotoxic Lymphocytes Cleaves GSDMB to Trigger Pyroptosis in Target Cells. Science (2020) 368(6494):eaaz7548. doi: 10.1126/science.aaz7548

54. Watabe K, Ito A, Asada H, Endo Y, Kobayashi T, Nakamoto K, et al. StructureExpression and Chromosome Mapping of MLZE, a Novel Gene Which Is Preferentially Expressed in Metastatic Melanoma Cells. Jpn J Cancer Res (2001) 92(2):140-51. doi: 10.1111/j.1349-7006.2001. tb01076.x

55. Hou J, Zhao R, Xia W, Chang C-W, You Y, Hsu J-M, et al. PD-L1-Mediated Gasdermin C Expression Switches Apoptosis to Pyroptosis in Cancer Cells and Facilitates Tumour Necrosis. Nat Cell Biol (2020) 22(10):1264-75. doi: $10.1038 / \mathrm{s} 41556-020-0575-\mathrm{Z}$

56. Elmore S. Apoptosis A Review of Programmed Cell Death. Toxicol Pathol (2007) 35(4):495-516. doi: 10.1080/01926230701320337

57. Kaarniranta K, Tokarz P, Koskela A, Paterno J, Blasiak J. Autophagy Regulates Death of Retinal Pigment Epithelium Cells in Age-Related Macular Degeneration. Cell Biol Toxicol (2017) 33(2):113-28. doi: 10.1007/s10565-0169371-8

58. Degterev A, Yuan J. Expansion and Evolution of Cell Death Programmes. Nat Rev Mol Cell Biol (2008) 9(5):378-90. doi: 10.1038/nrm2393

59. Royce GH, Brown-Borg HM, Deepa SS. The Potential Role of Necroptosis in Inflammaging and Aging. Geroscience (2019) 41(6):795-811. doi: 10.1007/ s11357-019-00131-w
60. Kerr JF, Wyllie AH, Currie AR. Apoptosis: A Basic Biological Phenomenon With Wide-Ranging Implications in Tissue Kinetics. Br J Cancer (1972) 26 (4):239-57. doi: 10.1038/bjc.1972.3

61. Kim KH, Lee MS. Autophagy-a Key Player in Cellular and Body Metabolism. Nat Rev Endocrinol (2014) 10(6):322-37. doi: 10.1038/ nrendo. 2014.35

62. Frank D, Vince JE. Pyroptosis Versus Necroptosis: Similarities, Differences, and Crosstalk. Cell Death Differ (2019) 26(1):99-114. doi: 10.1038/s41418018-0212-6

63. Flores-Romero H, Ros U, Garcia-Saez AJ. Pore Formation in Regulated Cell Death. EMBO J (2020) 39(23):e105753. doi: 10.15252/embj.2020105753

64. Zhang Y, Chen X, Gueydan C, Han J. Plasma Membrane Changes During Programmed Cell Deaths. Cell Res (2018) 28(1):9-21. doi: 10.1038/ cr.2017.133

65. Sauler M, Bazan IS, Lee PJ. Cell Death in the Lung: The ApoptosisNecroptosis Axis. Annu Rev Physiol (2019) 81:375-402. doi: 10.1146/ annurev-physiol-020518-114320

66. Glick D, Barth S, Macleod KF. Autophagy: Cellular and Molecular Mechanisms. J Pathol (2010) 221(1):3-12. doi: 10.1002/path.2697

67. Deng M, Tang Y, Li W, Wang X, Zhang R, Zhang X, et al. The Endotoxin Delivery Protein HMGB1 Mediates Caspase-11-Dependent Lethality in Sepsis. Immunity (2018) 49(4):740-53.e747. doi: 10.1016/j.immuni. 2018.08.016

68. Kabakov AE, Gabai VL. Cell Death and Survival Assays. Methods Mol Biol (2018) 1709:107-27. doi: 10.1007/978-1-4939-7477-1_9

69. Rieger AM, Nelson KL, Konowalchuk JD, Barreda DR. Modified Annexin V/ propidium Iodide Apoptosis Assay for Accurate Assessment of Cell Death. J Vis Exp (2011) 50:2597. doi: 10.3791/2597

70. Chen W, Zheng R, Baade PD, Zhang S, Zeng H, Bray F, et al. Cancer Statistics in China, 2015. CA Cancer J Clin (2016) 66(2):115-32. doi: $10.3322 /$ caac. 21338

71. Stein Y, Rotter V, Aloni-Grinstein R. Gain-Of-Function Mutant P53 All the Roads Lead to Tumorigenesis. Int J Mol Sci (2019) 20(24):6197. doi: 10.3390/ ijms20246197

72. Meek DW. Regulation of the P53 Response and Its Relationship to Cancer1. Biochem J (2015) 469(3):325-46. doi: 10.1042/BJ20150517

73. Bourdon J-C. P53 and Its Isoforms in Cancer. Br J Cancer (2007) 97(3):27782. doi: $10.1038 /$ sj.bjc. 6603886

74. Zhang T, Li Y, Zhu R, Song P, Wei Y, Liang T, et al. Transcription Factor P53 Suppresses Tumor Growth by Prompting Pyroptosis in Non-Small-Cell Lung Cancer. Oxid Med Cell Longev (2019) 2019:8746895. doi: 10.1155/ 2019/8746895

75. Gao J, Qiu X, Xi G, Liu H, Zhang F, Lv T, et al. Downregulation of GSDMD Attenuates Tumor Proliferation via the Intrinsic Mitochondrial Apoptotic Pathway and Inhibition of EGFR/Akt Signaling and Predicts a Good Prognosis in Nonsmall Cell Lung Cancer. Oncol Rep (2018) 40(4):197184. doi: $10.3892 /$ or. 2018.6634

76. Galluzzi LS L, Vitale I, Michels J, Martins I, Kepp O, Castedo M, et al. Molecular Mechanisms of Cisplatin Resistance. Oncogene (2011) 31 (15):1869-83. doi: 10.1038/onc.2011.384

77. Weaver BA. How Taxol Paclitaxel Kills Cancer Cells. Mol Biol Cell (2014) 25 (18):2677-81. doi: 10.1091/mbc.E14-04-0916

78. Fennell DA, Summers Y, Cadranel J, Benepal T, Christoph DC, Lal R, et al. Cisplatin in the Modern Era: The Backbone of First-Line Chemotherapy for non-Small Cell Lung Cancer. Cancer Treat Rev (2016) 44:42-50. doi: 10.1016/j.ctrv.2016.01.003

79. Zhang CC, Li CG, Wang YF, Xu LH, He XH, Zeng QZ, et al. Chemotherapeutic Paclitaxel and Cisplatin Differentially Induce Pyroptosis in A549 Lung Cancer Cells via Caspase-3/GSDME Activation. Apoptosis (2019) 24(3-4):312-25. doi: 10.1007/s10495-019-01515-1

80. Peng Z, Wang P, Song W, Yao Q, Li Y, Liu L, et al. GSDME Enhances Cisplatin Sensitivity to Regress non-Small Cell Lung Carcinoma by Mediating Pyroptosis to Trigger Antitumor Immunocyte Infiltration. Signal Transduct Target Ther (2020) 5(1):159. doi: 10.1038/s41392-02000274-9

81. Huang W, Zou K, Xiong B. The Rhizome of Trillium Tschonoskii Maxim. Extract Induces Apoptosis in Human Lung Cancer Cells. Z Naturforsch C J Biosci (2011) 66(9-10):477-84. doi: 10.1515/znc-2011-9-1007 
82. Qian S, Tong S, Wu J, Tian L, Qi Z, Chen B, et al. Paris Saponin VII Extracted From Trillium Tschonoskii Induces Autophagy and Apoptosis in NSCLC Cells. J Ethnopharmacol (2020) 248:112304. doi: 10.1016/ j.jep.2019.112304

83. Teng JF, Mei QB, Zhou XG, Tang Y, Xiong R, Qiu WQ, et al. Polyphyllin VI Induces Caspase-1-Mediated Pyroptosis via the Induction of ROS/NFKappab/NLRP3/GSDMD Signal Axis in Non Small Cell Lung Cancer. Cancers (Basel) (2020) 12(1):193. doi: 10.3390/cancers12010193

84. Zhang N, Kong X, Yan S, Yuan C, Yang Q. Huaier Aqueous Extract Inhibits Proliferation of Breast Cancer Cells by Inducing Apoptosis. Cancer Sci (2010) 101(11):2375-83. doi: 10.1111/j.1349-7006.2010.01680.x

85. Xie J, Zhuan B, Wang H, Wang Y, Wang X, Yuan Q, et al. Huaier Extract Suppresses Non-Small Cell Lung Cancer Progression Through Activating NLRP3-Dependent Pyroptosis. Anat Rec (Hoboken) (2021) 304(2):291-301. doi: 10.1002/ar.24307

86. Simpson E, Brown HL. Understanding Osteosarcomas. JAAPA (2018) 31 (8):15-9. doi: 10.1097/01.JAA.0000541477.24116.8d

87. Gianferante DM, Mirabello L, Savage SA. Germline and Somatic Genetics of Osteosarcoma - Connecting Aetiology, Biology and Therapy. Nat Rev Endocrinol (2017) 13(8):480-91. doi: 10.1038/nrendo.2017.16

88. Kansara M, Teng MW, Smyth MJ, Thomas DM. Translational Biology of Osteosarcoma. Nat Rev Cancer (2014) 14(11):722-35. doi: 10.1038/nrc3838

89. Wang Q, Jiang Y, Guo R, Lv R, Liu T, Wei H, et al. Physcion 8-O-BetaGlucopyranoside Suppresses Tumor Growth of Hepatocellular Carcinoma by Downregulating PIM1. BioMed Pharmacother (2017) 92:451-8. doi: 10.1016/j.biopha.2017.05.110

90. Dong X, Fu J, Yin X, Cao S, Li X, Lin L, et al. Emodin: A Review of Its Pharmacology, Toxicity and Pharmacokinetics. Phytother Res (2016) 30 (8):1207-18. doi: 10.1002/ptr.5631

91. Tian B, Hua Z, Wang Z, Wang J. Physcion 8-O-Beta-Glucopyranoside Mediates the NLRP3-Associated Pyroptosis and Cell Metastasis in the Human Osteosarcoma Cells via ER Stress Activation. Naunyn Schmiedebergs Arch Pharmacol (2021) 394(3):555. doi: 10.1007/s00210020-01836-y

92. Yin W, Liu S, Dong M, Liu Q, Shi C, Bai H, et al. A New NLRP3 Inflammasome Inhibitor, Dioscin, Promotes Osteogenesis. Small (2020) 16 (1):e1905977. doi: 10.1002/smll.201905977

93. Yang L, Ren S, Xu F, Ma Z, Liu X, Wang L. Recent Advances in the Pharmacological Activities of Dioscin. BioMed Res Int (2019) 2019:5763602. doi: $10.1155 / 2019 / 5763602$

94. Tao X, Yin L, Xu L, Peng J. Dioscin: A Diverse Acting Natural Compound With Therapeutic Potential in Metabolic Diseases, Cancer, Inflammation and Infections. Pharmacol Res (2018) 137:259-69. doi: 10.1016/ j.phrs.2018.09.022

95. Ding Q, Zhang W, Cheng C, Mo F, Chen L, Peng G, et al. Dioscin Inhibits the Growth of Human Osteosarcoma by Inducing G2/M-Phase Arrest, Apoptosis, and GSDME-Dependent Cell Death In Vitro and In Vivo. J Cell Physiol (2020) 235(3):2911-24. doi: 10.1002/jcp.29197

96. Tian BG, Hua Z, Wang ZJ, Li J. Knockdown of microRNA-181a Inhibits Osteosarcoma Cells Growth and Invasion Through Triggering NLRP3Dependent Pyroptosis. Eur Rev Med Pharmacol Sci (2020) 24(15):7922. doi: 10.26355/eurrev_202008_22457

97. Lin R, Wang S, Huang Z, Chen H, Zhang S, Lin J, et al. Gasdermin D Expression and Clinicopathologic Outcome in Primary Osteosarcoma Patients. Int J Clin Exp Pathol (2020) 13(12):3149-57. Hongxiang Wei.

98. Anastasiadi Z, Harissis VH, Lianos GD, Mitsis M, Ignatiadou E. Breast Cancer in Young Women an Overview. Updates Surg (2016) 69(3):313-7. doi: 10.1007/s13304-017-0424-1

99. Akram M IM, Daniyal M, Khan AU. Awareness and Current Knowledge of Breast Cancer. Biol Res (2017) 50(1):33. doi: 10.1186/s40659-017-0140-9

100. Ghoncheh M, Pournamdar Z, Salehiniya H. Incidence and Mortality and Epidemiology of Breast Cancer in the World. Asian Pac J Cancer Prev (2016) 17(S3):43-6. doi: 10.7314/APJCP.2016.17.Special

101. Wu X, Mao Xu, Huang Y, Zhu Q, Guan J, Wu L. Detection of Proteins Associated With the Pyroptosis Signaling Pathway in Breast Cancer Tissues and Their Significance. Int J Clin Exp Pathol (2010) 13(6):1408-14.

102. Kang KiS, Wang P, Yamabe N, Fukui M, Jay T, Zhu BT. Docosahexaenoic Acid Induces Apoptosis in MCF-7 Cells In Vitro and In Vivo via Reactive
Oxygen Species Formation and Caspase 8 Activation. PloS One (2010) 5(4): e10296. doi: 10.1371/journal.pone.0010296

103. Blanckaert V, Ulmann L, Mimouni V, Antol J, Brancquart L, Chénais B. Docosahexaenoic Acid Intake Decreases Proliferation Increases Apoptosis and Decreases the Invasive Potential of the Human Breast Carcinoma Cell Line MDA-MB-231. Int J Oncol (2010) 36(3):737-42. doi: 10.3892/ ijo_00000549

104. Pizato N, Luzete BC, Kiffer LFMV, Corrêa LH, de Oliveira Santos I, Assumpção JAF, et al. Omega-3 Docosahexaenoic Acid Induces Pyroptosis Cell Death in Triple-Negative Breast Cancer Cells. Sci Rep (2018) 8(1):1952. doi: 10.1038/s41598-018-20422-0

105. Cristescu R, Mogg R, Ayers M, Albright A, Murphy E, Yearley J, et al. Cancer Immunotherapy Using Checkpoint Blockade. Science (2018) 362(6411): eaar3593. doi: 10.1126/science.aar3593

106. Zhu X, Lang J. Soluble PD-1 and PD-L1 Predictive and Prognostic Significance in Cancer. Oncotarget (2017) 8(57):97671-82. doi: 10.18632/ oncotarget.18311

107. Powles T, Eder JP, Fine GD, Braiteh FS, Loriot Y, Cruz C, et al. MPDL3280A (Anti-PD-L1) Treatment Leads to Clinical Activity in Metastatic Bladder Cancer. Nature (2014) 515(7528):558-62. doi: 10.1038/nature13904

108. Socinski MA, Jotte R, Cappuzzo F, Orlandi F, Stroyakovskiy D, Nogami N, et al. Atezolizumab for First-Line Treatment of Metastatic Nonsquamous NSCLC. N Engl J Med (2018) 378(24):2288-301. doi: 10.1056/ NEJMoa1716948

109. Ghebeh H, Lehe C, Barhoush E, Al-Romaih K, Tulbah A, Al-Alwan M, et al. Doxorubicin Downregulates Cell Surface B7-H1 Expression and Upregulates Its Nuclear Expression in Breast Cancer Cells: Role of B7-H1 as an AntiApoptotic Molecule. Breast Cancer Res (2010) 12(4):R48. doi: 10.1186/ bcr 2605

110. Satelli A, Batth IS, Brownlee Z, Rojas C, Meng QH, Kopetz S, et al. Potential Role of Nuclear PD-L1 Expression in Cell-Surface Vimentin Positive Circulating Tumor Cells as a Prognostic Marker in Cancer Patients. Sci Rep (2016) 6:28910. doi: 10.1038/srep28910

111. Mattiuzzi C, Lippi G. Cancer Statistics: A Comparison Between World Health Organization (WHO) and Global Burden of Disease (GBD). Eur J Public Health (2020) 30(5):1026-7. doi: 10.1093/eurpub/ckz216

112. Jie B, Qiu Y, Feng ZZ, Zhu SN. Impact of Disclosure of Diagnosis and Patient Autonomy on Quality of Life and Illness Perceptions in Chinese Patients With Liver Cancer. Psychooncology (2016) 25(8):927-32. doi: 10.1002/ pon.4036

113. Waller A, Forshaw K, Bryant J, Mair S. Interventions for Preparing Patients for Chemotherapy and Radiotherapy: A Systematic Review. Support Care Cancer (2014) 22(8):2297-308. doi: 10.1007/s00520-014-2303-3

114. Zhang Y, Yang H, Sun M, He T, Liu Y, Yang X, et al. Alpinumisoflavone Suppresses Hepatocellular Carcinoma Cell Growth and Metastasis via NLRP3 Inflammasome-Mediated Pyroptosis. Pharmacol Rep (2020) 72 (5):1370-82. doi: 10.1007/s43440-020-00064-8

115. Wei Q, Mu K, Li T, Zhang Y, Yang Z, Jia X, et al. Deregulation of the NLRP3 Inflammasome in Hepatic Parenchymal Cells During Liver Cancer Progression. Lab Invest (2014) 94(1):52-62. doi: 10.1038/labinvest. 2013.126

116. Wei Q, Zhu R, Zhu J, Zhao R, Li M. E2-Induced Activation of the NLRP3 Inflammasome Triggers Pyroptosis and Inhibits Autophagy in HCC Cells. Oncol Res (2019) 27(7):827-34. doi: 10.3727/096504018X15462920753012

117. Han Y, Yang X, Zhao N, Peng J, Gao H, Qiu X. Alpinumisoflavone Induces Apoptosis in Esophageal Squamous Cell Carcinoma by Modulating miR-370 PIM1 Signaling. Am J Cancer Res (2016) 6(12):2755-71.

118. Li D, Li X, Li G, Meng Y, Jin Y, Shang S, et al. Alpinumisoflavone Causes DNA Damage in Colorectal Cancer Cells via Blocking DNA Repair Mediated by RAD51. Life Sci (2019) 216:259-70. doi: 10.1016/ j.lfs.2018.11.032

119. Lin LL, Huang F, Chen SB, Yang DJ, Chen SL, Yang JS, et al. Xanthones From the Roots of Polygala Caudata and Their Antioxidation and Vasodilatation Activities In Vitro. Planta Med (2005) 71(4):372-5. doi: $10.1055 /$ s-2005-864108

120. Wang N, Zhou F, Guo J, Zhu H, Luo S, Cao J. Euxanthone Suppresses Tumor Growth and Metastasis in Colorectal Cancer via Targeting CIP2A/PP2A Pathway. Life Sci (2018) 209:498-506. doi: 10.1016/j.lfs.2018.08.052 
121. Zou J, Wang Y, Liu M, Huang X, Zheng W, Gao Q, et al. Euxanthone Inhibits Glycolysis and Triggers Mitochondria-Mediated Apoptosis by Targeting Hexokinase 2 in Epithelial Ovarian Cancer. Cell Biochem Funct (2018) 36 (6):303-11. doi: 10.1002/cbf.3349

122. Chen Y-F, Qi H-Y, Wu F-L. Euxanthone Exhibits Anti-Proliferative and Anti-Invasive Activities in Hepatocellular Carcinoma by Inducing Pyroptosis Preliminary Results. Eur Rev Med Pharmacol Sci (2018) 22 (23):8186-96. doi: 10.26355/eurrev_201812_16511

123. Karimi P, Islami F, Anandasabapathy S, Freedman ND, Kamangar F. Gastric Cancer: Descriptive Epidemiology, Risk Factors, Screening, and Prevention. Cancer Epidemiol Biomarkers Prev (2014) 23(5):700-13. doi: 10.1158/10559965.EPI-13-1057

124. Wang FH, Shen L, Li J, Zhou ZW, Liang H, Zhang XT, et al. The Chinese Society of Clinical Oncology (CSCO): Clinical Guidelines for the Diagnosis and Treatment of Gastric Cancer. Cancer Commun (Lond) (2019) 39(1):10. doi: 10.1186/s40880-019-0349-9

125. Xia X, Wang X, Cheng Z, Qin W, Lei L, Jiang J, et al. The Role of Pyroptosis in Cancer: Pro-Cancer or Pro-"Host"? Cell Death Dis (2019) 10(9):650. doi: 10.1038/s41419-019-1883-8

126. Wang Y, Yin B, Li D, Wang G, Han X, Sun X. GSDME Mediates Caspase-3Dependent Pyroptosis in Gastric Cancer. Biochem Biophys Res Commun (2018) 495(1):1418-25. doi: 10.1016/j.bbrc.2017.11.156

127. Deng BB, Jiao BP, Liu YJ, Li YR, Wang GJ. BIX-01294 Enhanced Chemotherapy Effect in Gastric Cancer by Inducing GSDME-Mediated Pyroptosis. Cell Biol Int (2020) 44(9):1890-9. doi: 10.1002/cbin.11395

128. Wang WJ, Chen Di, Jiang MZ, Xu B, Li XW, Chu Yi, et al. Downregulation of GSDMD Promotes Gastric Cancer Proliferation by Regulating Cell CycleRelated Proteins. J Dig Dis (2018) 19(2):74-83. doi: 10.1002/cdd.12576

129. Nogata Y, Shiratsuchi H, Ishii T, Yano M, Ohta H. Flavonoid Composition of Fruit Tissues of Citrus Species. Biosci Biotechnol Biochem (2006) 70(1):17892. doi: 10.1271/bbb.70.178 Koji Sakamoto.

130. Chen J, Chen AY, Huang H, Ye X, Rollyson WD, Perry HE, et al. The Flavonoid Nobiletin Inhibits Tumor Growth and Angiogenesis of Ovarian Cancers via the Akt Pathway. Int J Oncol (2015) 46(6):2629-38. doi: 10.3892/ijo.2015.2946

131. Jiang YP, Guo H, Wang XB. Nobiletin (NOB) Suppresses Autophagic Degradation via Over-Expressing AKT Pathway and Enhances Apoptosis in Multidrug-Resistant SKOV3/TAX Ovarian Cancer Cells. BioMed Pharmacother (2018) 103:29-37. doi: 10.1016/j.biopha.2018.03.126

132. Zhang R, Chen J, Mao L, Guo Y, Hao Y, Deng Y, et al. Nobiletin Triggers Reactive Oxygen Species-Mediated Pyroptosis Through Regulating Autophagy in Ovarian Cancer Cells. J Agric Food Chem (2020) 68 (5):1326-36. doi: 10.1021/acs.jafc.9b07908

133. Wang K, Johnson A, Ali SM, Klempner SJ, Bekaii-Saab T, Vacirca JL, et al. Comprehensive Genomic Profiling of Advanced Esophageal Squamous Cell Carcinomas and Esophageal Adenocarcinomas Reveals Similarities and Differences. Oncologist (2015) 20(10):1132-9. doi: 10.1634/theoncologist.20150156

134. Pernicova I, Korbonits M. Metformin-mode of Action and Clinical Implications for Diabetes and Cancer. Nat Rev Endocrinol (2014) 10 (3):143-56. doi: 10.1038/nrendo.2013.256

135. Wang L, Li K, Lin X, Yao Z, Wang S, Xiong X, et al. Metformin Induces Human Esophageal Carcinoma Cell Pyroptosis by Targeting the miR-497/ PELP1 Axis. Cancer Lett (2019) 450:22-31. doi: 10.1016/j.canlet.2019.02.014

136. Yu S, Zhao N, He M, Zhang K, Bi X. MiRNA-214 Promotes the Pyroptosis and Inhibits the Proliferation of Cervical Cancer Cells via Regulating the Expression of NLRP3. Cell Mol Biol (2020) 66(6):59-64. doi: 10.14715/cmb/ 2020.66.6.11

137. Braun MM, Overbeek-WagerEA, Grumbo RJ. Diagnosis and Management of Endometrial Cancer. Am Fam Physician (2016) 93(6):468-74.

138. Yang Y, Liu PY, Bao W, Chen SJ, Wu FS, Zhu PY. Hydrogen Inhibits Endometrial Cancer Growth via a ROS/NLRP3/caspase-1/GSDMDMediated Pyroptotic Pathway. BMC Cancer (2020) 20(1):28. doi: 10.1186/ s12885-019-6491-6

139. Siegel RL, Miller KD, Jemal A. Cancer Statistics, 2016. CA Cancer J Clin (2016) 66(1):7-30. doi: 10.3322/caac.21332

140. Cui J, Zhou Z, Yang H, Jiao F, Li N, Gao Y, et al. MST1 Suppresses Pancreatic Cancer Progression via ROS-Induced Pyroptosis. Mol Cancer Res (2019) 17 (6):1316-25. doi: 10.1158/1541-7786.MCR-18-0910
141. Zhou CB, Fang JY. The Role of Pyroptosis in Gastrointestinal Cancer and Immune Responses to Intestinal Microbial Infection. Biochim Biophys Acta Rev Cancer (2019) 1872(1):1-10. doi: 10.1016/j.bbcan.2019.05.001

142. Lasry A, Zinger A, Ben-Neriah Y. Inflammatory Networks Underlying Colorectal Cancer. Nat Immunol (2016) 17(3):230-40. doi: 10.1038/ni.3384

143. Tan G, Huang C, Chen J, Zhi F. HMGB1 Released From GSDME-Mediated Pyroptotic Epithelial Cells Participates in the Tumorigenesis of ColitisAssociated Colorectal Cancer Through the ERK1/2 Pathway. J Hematol Oncol (2020) 13(1):149. doi: 10.1186/s13045-020-00985-0

144. Okondo MC, Johnson DC, Sridharan R, Go EB, Chui AJ, Wang MS, et al. DPP8 and DPP9 Inhibition Induces Pro-Caspase-1-Dependent Monocyte and Macrophage Pyroptosis. Nat Chem Biol (2017) 13(1):46-53. doi: $10.1038 /$ nchembio.2229

145. Taabazuing CY, Okondo MC, Bachovchin DA. Pyroptosis and Apoptosis Pathways Engage in Bidirectional Crosstalk in Monocytes and Macrophages. Cell Chem Biol (2017) 24(4):507-514 e504. doi: 10.1016/j.chembiol. 2017.03.009

146. Johnson DC, Taabazuing CY, Okondo MC, Chui AJ, Rao SD, Brown FC, et al. DPP8/DPP9 Inhibitor-Induced Pyroptosis for Treatment of Acute Myeloid Leukemia. Nat Med (2018) 24(8):1151-6. doi: 10.1038/s41591-0180082-y

147. Zhang Z, Zhang Y, Lieberman J. Lighting a Fire: Can We Harness Pyroptosis to Ignite Antitumor Immunity? Cancer Immunol Res (2021) 9(1):2-7. doi: 10.1158/2326-6066.CIR-20-0525

148. Tsuchiya K. Switching From Apoptosis to Pyroptosis: Gasdermin-Elicited Inflammation and Antitumor Immunity. Int J Mol Sci (2021) 22(1):426. doi: 10.3390/ijms22010426

149. Tang R, Xu J, Zhang B, Liu J, Liang C, Hua J, et al. Ferroptosis, Necroptosis, and Pyroptosis in Anticancer Immunity. J Hematol Oncol (2020) 13(1):110. doi: 10.1186/s13045-020-00946-7

150. Rosenbaum SR, Wilski NA, Aplin AE. Fueling the Fire: Inflammatory Forms of Cell Death and Implications for Cancer Immunotherapy. Cancer Discovery (2021) 11(2):266-81. doi: 10.1158/2159-8290.CD-200805

151. Erkes DA, Cai W, Sanchez IM, Purwin TJ, Rogers C, Field CO, et al. Mutant BRAF and MEK Inhibitors Regulate the Tumor Immune Microenvironment via Pyroptosis. Cancer Discovery (2020) 10(2):254-69. doi: 10.1158/21598290.CD-19-0672

152. Blessin NC, Spriestersbach P, Li W, Mandelkow T, Dum D, Simon R, et al. Prevalence of CD8(+) Cytotoxic Lymphocytes in Human Neoplasms. Cell Oncol (Dordr) (2020) 43(3):421-30. doi: 10.1007/ s13402-020-00496-7

153. Stanton SE, Disis ML. Clinical Significance of Tumor-Infiltrating Lymphocytes in Breast Cancer. J Immunother Cancer (2016) 4:59. doi: 10.1186/s40425-016-0165-6

154. Lang JD, Matute-Bello G. Lymphocytes, Apoptosis and Sepsis: Making the Jump From Mice to Humans. Crit Care (2009) 13(1):109. doi: 10.1186/ cc7144

155. Wang Q, Wang Y, Ding J, Wang C, Zhou X, Gao W, et al. A Bioorthogonal System Reveals Antitumour Immune Function of Pyroptosis. Nature (2020) 579(7799):421-6. doi: 10.1038/s41586-020-2079-1

156. Atrash S, Bano K, Harrison B, Abdallah AO. CAR-T Treatment for Hematological Malignancies. J Investig Med (2020) 68(5):956-64. doi: 10.1136/jim-2020-001290

157. Brudno JN, Kochenderfer JN. Recent Advances in CAR T-Cell Toxicity: Mechanisms, Manifestations and Management. Blood Rev (2019) 34:45-55. doi: 10.1016/j.blre.2018.11.002

158. Holstein SA, Lunning MA. CAR T-Cell Therapy in Hematologic Malignancies: A Voyage in Progress. Clin Pharmacol Ther (2020) 107 (1):112-22. doi: 10.1002/cpt.1674

159. Zhang C, Liu J, Zhong JF, Zhang X. Engineering CAR-T Cells. Biomark Res (2017) 5:22. doi: 10.1186/s40364-017-0102-y

160. Sheth VS, Gauthier J. Taming the Beast: CRS and ICANS After CAR T-Cell Therapy for ALL. Bone Marrow Transplant (2021) 56(3):552-66. doi: 10.1038/s41409-020-01134-4

161. Shimabukuro-Vornhagen A, Godel P, Subklewe M, Stemmler HJ, Schlosser HA, Schlaak M, et al. Cytokine Release Syndrome. J Immunother Cancer (2018) 6(1):56. doi: 10.1186/s40425-018-0343-9 
162. Giavridis T, van der Stegen SJC, Eyquem J, Hamieh M, Piersigilli A, Sadelain M. CAR T Cell-Induced Cytokine Release Syndrome Is Mediated by Macrophages and Abated by IL-1 Blockade. Nat Med (2018) 24(6):731-8. doi: 10.1038/s41591-018-0041-7

163. Liu Y, Fang Y, Chen X, Wang Z, Liang X, Zhang T, et al. Gasdermin E-Mediated Target Cell Pyroptosis by CAR T Cells Triggers Cytokine Release Syndrome. Sci Immunol (2020) 5(43):eaax7969. doi: 10.1126/ sciimmunol.aax7969

164. Broz P, Pelegrin P, Shao F. The Gasdermins, a Protein Family Executing Cell Death and Inflammation. Nat Rev Immunol (2020) 20(3):143-57. doi: 10.1038/s41577-019-0228-2

165. Feng S, Fox D, Man SM. Mechanisms of Gasdermin Family Members in Inflammasome Signaling and Cell Death. J Mol Biol (2018) 430(18 Pt B):3068-80. doi: 10.1016/j.jmb.2018.07.002

166. Aglietti RA, Dueber EC. Recent Insights Into the Molecular Mechanisms Underlying Pyroptosis and Gasdermin Family Functions. Trends Immunol (2017) 38(4):261-71. doi: 10.1016/j.it.2017.01.003

167. Man SM, Karki R, Kanneganti TD. Molecular Mechanisms and Functions of Pyroptosis, Inflammatory Caspases and Inflammasomes in Infectious Diseases. Immunol Rev (2017) 277(1):61-75. doi: 10.1111/ imr. 12534

168. Liu L, Sun B. Neutrophil Pyroptosis: New Perspectives on Sepsis. Cell Mol Life Sci (2019) 76(11):2031-42. doi: 10.1007/s00018-019-03060-1
169. Xu YJ, Zheng L, Hu YW, Wang Q. Pyroptosis and Its Relationship to Atherosclerosis. Clin Chim Acta (2018) 476:28-37. doi: 10.1016/ j.cca.2017.11.005

170. Jia C, Chen H, Zhang J, Zhou K, Zhuge Y, Niu C, et al. Role of Pyroptosis in Cardiovascular Diseases. Int Immunopharmacol (2019) 67:311-8. doi: 10.1016/j.intimp.2018.12.028\#

Conflict of Interest: The authors declare that the research was conducted in the absence of any commercial or financial relationships that could be construed as a potential conflict of interest.

Publisher's Note: All claims expressed in this article are solely those of the authors and do not necessarily represent those of their affiliated organizations, or those of the publisher, the editors and the reviewers. Any product that may be evaluated in this article, or claim that may be made by its manufacturer, is not guaranteed or endorsed by the publisher.

Copyright (c) $2021 \mathrm{Wu}$, Wei, Li, Yang and Zhou. This is an open-access article distributed under the terms of the Creative Commons Attribution License (CC BY). The use, distribution or reproduction in other forums is permitted, provided the original author(s) and the copyright owner(s) are credited and that the original publication in this journal is cited, in accordance with accepted academic practice. No use, distribution or reproduction is permitted which does not comply with these terms. 